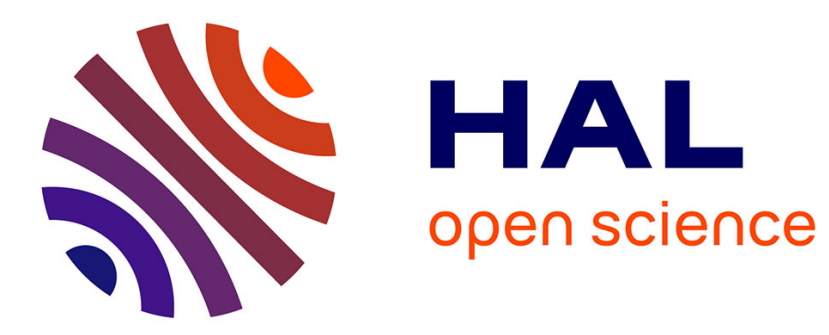

\title{
Diagnosis of the productivity gap using a crop model. Methodology and case study of small-scale maize production in central Brazil
}

François Affholder, Eric Scopel, Jose Neto, Alain Capillon

\section{- To cite this version:}

François Affholder, Eric Scopel, Jose Neto, Alain Capillon. Diagnosis of the productivity gap using a crop model. Methodology and case study of small-scale maize production in central Brazil. Agronomie, 2003, 23 (4), pp.305-325. 10.1051/agro:2003004 . hal-00886183

\section{HAL Id: hal-00886183 https://hal.science/hal-00886183}

Submitted on 1 Jan 2003

HAL is a multi-disciplinary open access archive for the deposit and dissemination of scientific research documents, whether they are published or not. The documents may come from teaching and research institutions in France or abroad, or from public or private research centers.
L'archive ouverte pluridisciplinaire HAL, est destinée au dépôt et à la diffusion de documents scientifiques de niveau recherche, publiés ou non, émanant des établissements d'enseignement et de recherche français ou étrangers, des laboratoires publics ou privés. 


\title{
Diagnosis of the productivity gap using a crop model. Methodology and case study of small-scale maize production in central Brazil ${ }^{1}$
}

\author{
François AFFHOLDER ${ }^{a *}$, Eric SCOPEL ${ }^{\mathrm{b}}$, Jose MADEIRA NETO ${ }^{\mathrm{b}}$, Alain CAPILLON ${ }^{\mathrm{a}}$ \\ ${ }^{\text {a }}$ Cirad-CA, 73 rue Jean-François Breton, TA74/09, 34398 Montpellier Cedex 5, France \\ ${ }^{\mathrm{b}}$ Embrapa-Cerrados/CIRAD, BR20, km 18, CP08233, CEP 73301-970 Planaltina-DF, Brazil
}

(Received 18 January 2001; revised 28 September 2001 and 2 May 2002; accepted 17 September 2002)

\begin{abstract}
Reducing the local gap between potential and actual yields requires first diagnosing its causes. This article proposes a method for this purpose, based on a survey in farmers' fields and on the building and use of an ad hoc crop model. Applied to maize of small-scale farms in central Brazil, and using the STICS model as a starting point, this method allowed the identification of the constraints responsible for the local gap and to assess the specific impact of each constraint and of the main interactions between constraints on yield. STICS was modified in order (i) to improve its water balance module for the tropical context, and (ii) to account for Aluminum toxicity, water excess and competition between crop and weeds for light, water and nitrogen. The main technical weaknesses of the cropping systems were inappropriate sowing dates, $\mathrm{N}$-fertilization and weeding sequences, as well as delays between tillage and sowing, favoring weed growth.
\end{abstract}

yield gap / crop model / maize / diagnosis / constraints

Résumé - Diagnostic du déficit de productivité à l'aide d'un modèle de culture. Méthode et application au cas du maïs chez les petits producteurs du Brésil central. Réduire les écarts locaux entre rendements réels et potentiels impose d'en diagnostiquer d'abord les causes. Cet article propose une méthode pour cela, basée sur une enquête en parcelles de producteurs et sur la construction et l'emploi d'un modèle de culture ad hoc. Appliquée au maîs des petits producteurs du Brésil central, et avec le modèle STICS comme point de départ, cette méthode a permis d'identifier les contraintes responsables des écarts de productivité dans la région, et d'évaluer l'impact spécifique de chaque contrainte et des principales interactions entre contraintes sur le rendement. STICS a été modifié de manière à améliorer son module de bilan hydrique pour le contexte tropical et à prendre en compte la toxicité aluminique, l'excès d'eau et la compétition entre la culture et les mauvaises herbes pour le rayonnement, l'eau et l'azote. Les principales faiblesses des systèmes de culture étaient l'inadaptation des dates de semis, des fertilisations azotées et des calendriers de sarclages, ainsi que des délais entre préparation du sol et semis favorisant la croissance des adventices.

étude du rendement / diagnostic / modèle de culture / maïs / contraintes

\section{INTRODUCTION}

One of the most common tasks in applied agronomy is the identification of the technical and environmental constraints limiting yields in a given area so that strategies can be designed to reduce the gap between potential and actual yields. However, no fully objective method exists for this purpose because, in most cases, the heterogeneity of the environment and of the technical management is great. The possible constraints on yields are so varied and their interaction so complex that the setting up of an experiment allowing adequate use of common statistical analysis is not feasible. One notable exception which confirms this is the work of Becker and Johnson [5] on irrigated rice in Côte d'Ivoire. The low variability of the water factor allowed these authors to build a structured on-farm device to assess the impact of Nitrogen fertilization and weed control on yields, which were the main varying aspects of crop management.

Given this difficulty, many studies are simply based on surveys in which farmers are asked to list the problems that they perceive [19]. In other cases, on-farm yield measurements are performed, technical management is monitored, and a

Communicated by Jean François Ledent (Louvain-la-Neuve, France)

\footnotetext{
${ }^{1}$ Work conducted as part of a cooperation project between CIRAD-CA (Centre de coopération internationale en recherche agronomique pour le développement, annual crops department) and EMBRAPA-Cerrados (Empresa Brasileira de Pesquisa Agropecuária, center for the Cerrados region). 
multi-variate analysis is conducted to detect statistical correlations between yield and management variables [23]. As Doré et al. pointed out [18], the latter two approaches are inadequate because they often erroneously identify cropping system characteristics as causes of its weakness, though they are actually only symptoms. Let us consider, for example, a region where, because of incorrect seedbed preparation, plant density is low, which in turn results in high weed infestation. Questioned farmers would probably say that weed control is one of their main problems. Statistical analyses crossing technical management with yields may also show a correlation between the yield and the amount of weeding done by farmers. Both approaches would thus probably result in a wrong diagnosis and lead to inappropriate corrective action, such as the diffusion of new weeding techniques or tools, whereas support for farmers focusing on tillage would be more adequate. Several other examples of incorrect diagnoses resulting from these approaches are given by Doré et al. [18].

Alternatively, and summarizing numerous case studies, these authors proposed a general methodology for agronomic diagnosis. Yield variations observed in a multi-annual on-farm survey are analyzed with reference to a crop-yield build-up model. The model helps to assess causal relationships, instead of correlations, between measurements of possible constraints on one hand, and the chronology and importance of the observed growth reductions relative to potential growth on the other. The chronology of growth reductions is established by measuring the size and number of plant organs (yield components, such as ears and kernels for cereals) that are built at specific stages of the growth cycle, and by comparing them with their potential values. The model referred to by these authors combines a conceptual model (in fact, the agronomic theory for the crop studied) with dynamic simulation models. The conceptual part of the model provides qualitative information on the phenological stage at which the crop is sensitive to a given constraint, the organs affected by said constraint, and a list of environmental and crop characteristics that determine the occurrence of the constraint. In most of the studies applying this method, the quantitative part of the model simulates only the potential yield components $[4,6,27$, $30,43]$. In a few cases, however, a water balance simulation model is also used to quantify the intensity and the date of occurrence of the water constraint [16, 26, 37]. But in all these cases, due to the fact that the model is at least partially conceptual, it does not quantitatively assess the impact of the constraints on yields, nor the interactions between constraints.

As a result, when several constraints are suspected and are known to influence growth at the same growing stages, it is difficult to infer the consequences of each one on yields. In some cases, sub-samples of farmers' fields may be designed with and without the occurrence of one of the constraints, allowing better assessment of its specific influence on yields. However, especially when the possible constraints are numerous and combined in the fields, as is generally the case in small-scale farming in developing countries, such subsamples are not likely to be obtained with a sufficient number of repetitions in each of them. Therefore, in all the studies cited above, this method resulted in a hierarchy of constraints, mainly in terms of their frequency of occurrence (i.e. the frequency of fields in which a given constraint limited yield relative to potential), and not in terms of their impact on yield (i.e. the amount of decrease in yield due to a given constraint).

Nevertheless, the purpose of modern crop models is precisely to quantitatively simulate the effects of interacting constraints on yields. Most modelers nowadays admit that there is no universal model capable of predicting the yield of any genotype at any location [33, 40, 41]. However, robust models applicable to a broad range of environments and crops are available, that take into account some of the factors affecting yields. These are solar radiation, temperature and water and nitrogen constraints, towards which efforts have been directed since the earliest stages of crop modeling due to their major influence in most cropped situations. Moreover, the existing knowledge regarding many other constraints has already been integrated into process-oriented models. These more complex models, although not suitable in most cases for the on-farm context, due to their usually huge "appetite for data", may nevertheless serve as a basis for more empirical modeling tailored to the environment under study.

The purpose of this paper is to take advantage of the advances obtained in crop modeling to introduce some methodological innovations in the existing diagnostic method cited above, recognizing that some speculative aspects remain unavoidable. The general principle of these innovations is to obtain, by way of crop simulation, at least some of the experimental plots that would be necessary to allow a fully objective analysis, that would not take place, in a practical sense, in an on-farm device across a region. More precisely, two main uses of a simulation model for a diagnosis purpose may be identified. First, comparisons between actual and potential yields may be replaced by comparisons between actual yields and simulated yields. These simulated yields are those that would be obtained if the constraints accounted for by the model were the only limiting factors. This would reduce the number of constraints to be identified in the farmers' fields, and would therefore increase the size of the subsamples of fields differing by one constraint only. Second, for each actual cropped situation of a survey, simulations may be used to generate a virtual experiment in order to estimate to what extent yield is affected by each constraint considered by the model.

\section{MATERIALS AND METHODS}

\subsection{General approach}

The method is summarized in Figure 1. It starts with a review of the available knowledge on the region under study in order to provide the main hypothesis upon which the experimental device is based (Stage 0). Along with this preliminary analysis, the method comprises three stages: the use of a crop model ("initial model") for further identification of constraints limiting actual yields, but not accounted for by the model (Stage I), a modeling stage (Stage II) in which the model is enhanced in order to consider the constraints identified in Stage I, and lastly (Stage III), a sensitivity analysis of the new model ("modified model"). This last stage aims to evaluate the effects on the simulated yield of the main 


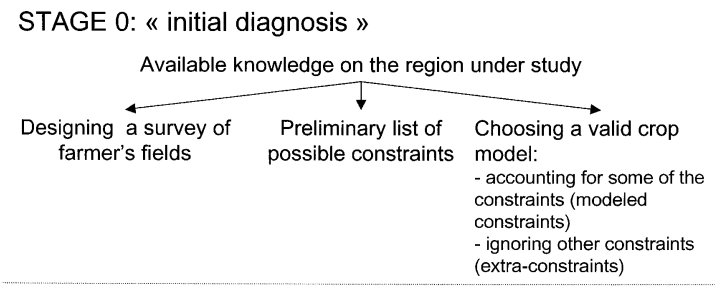

STAGE I: « diagnosis of constraint occurrences »

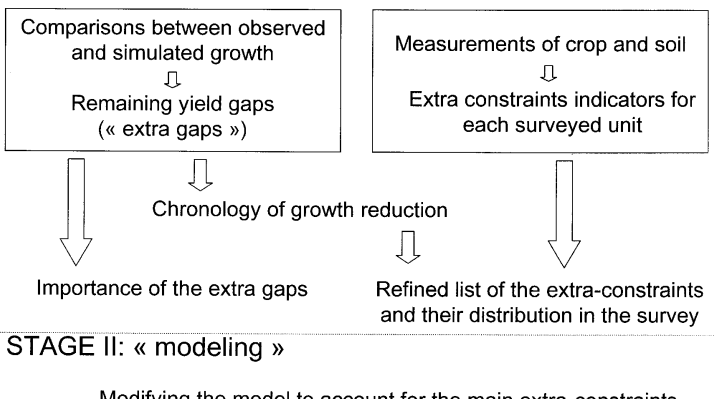

STAGE III: " diagnosis of the impact of constraints »

Assessing the role of all modeled constraints in simulated yield variations relative to yield potential

Figure 1. Methodology outline.

technical and environmental variables that are involved in the regional yield gap, given their distribution in the fields and considering their main interactions. All these stages utilize data from a multi-annual on-farm survey conducted on a plot sample taken from farmers' fields so that the regional diversity of cropping conditions is represented.

\subsection{Initial knowledge of the region under study (Stage 0)}

The Silvânia region was chosen for the testing of these principles $\left(16^{\circ} 46^{\prime} 43^{\prime \prime} \mathrm{S}, 48^{\circ} 51^{\prime} 21^{\prime \prime} \mathrm{W}\right)$. It is a municipality covering $2000 \mathrm{~km}^{2}$ in the state of Goiás, located in central Brazil (Cerrados region), where small dairy/maize farms predominate. A classical "green-revolution" technical package, that included the use of fertilizers, improved cultivars, and soil tillage machinery, had recently replaced cropping systems based on manual and animal-drawn tillage with no or very few inputs [8].

According to the methodology presented by Doré et al. [18], the available knowledge of the region was reviewed in order to identify: (i) an initial list of constraints possibly affecting local yields, and (ii) the main environmental and technical management variations for maize in the studied area. This review allowed the rationalization of the building of the on-farm survey device, as well as the choice of the initial model, and may be considered as a preliminary diagnosis. The sources of information were the available literature $[7,9,17$, 38] and also key informants such as researchers, technical engineers, and the farmers themselves. It was completed by a preliminary survey (performed within one week) including
Table I. List of all the constraints possibly occurring in Silvânia, and their suspected causes according to the initial knowledge available at the start of the study.

\begin{tabular}{ll}
\hline Constraint & Suspected causes \\
\hline water stress (W) & $\begin{array}{l}\text { dry period of varying duration that } \\
\text { frequently occurs in the middle of } \\
\text { the rainy season (veranico) }\end{array}$ \\
$\begin{array}{l}\text { nutrient availability: especially } \\
\text { nitrogen (N), and phosphorus (P), } \\
\text { and possibly potassium (K) }\end{array}$ & $\begin{array}{l}\text { low soil fertility } \\
\text { and low fertilizer use }\end{array}$ \\
low plant density (D) & low sowing density \\
Al toxicity/Ca deficiency (A) & nature of the soil \\
weeds (H) & $\begin{array}{l}\text { late weeding and incorrect soil } \\
\text { preparation }\end{array}$ \\
$\begin{array}{l}\text { other biotic stresses (OB) } \\
\text { (especially attacks by }\end{array}$ & lack of control \\
$\begin{array}{l}\text { Spodoptera } \text { spp.) } \\
\text { water excess (X) }\end{array}$ & high rainfall in poorly drained \\
\hline
\end{tabular}

descriptions of soil and root profiles, according to Manichon [29], from a set of 12 plots contrasted by soil conditions and maize growth as observable at flowering.

These sources indicated that maize yields were extremely variable in the region, ranging from 500 to $9000 \mathrm{~kg} / \mathrm{ha} \mathrm{[7]} \mathrm{and}$ it was suspected that, although also high, variations in the environment were not exclusively responsible for these variations, and that further improvements in technical management could fit yields better to the potentials allowed by each environment.

These sources also indicated that numerous possible constraints, listed in Table I, could a priori be suspected to occur in the region. Of this list, nitrogen $(\mathrm{N})$ and water (W) constraints and low plant densities (D constraint) were likely to be particularly strong and common, but no hierarchy between constraints was available at this stage.

Temperature and solar radiation were known to vary little in time and space [2]. The inter-annual and spatial variability of rainfall were, in contrast, high. Particularly, dry periods of varying duration, known as veranicos, were likely to occur in the middle of the growing season, and were considered as the major source of climatic risk for crops [2].

Soil classes according to soil taxonomy were providing poor information about the potentialities and constraints of the soils of the region, due to a very high intra-class variability of some essential characteristics such as soil depth and nutrient availability. Alternatively, the variability of both chemical and physical soil characteristics was known to depend on (i) the geologic substratum, and (ii) the position along the toposequence profile. Four geologic units and a maximum of three topo-sequence types were considered (Madeira, personal communication). The upper unit of the topo-sequence is lacking in two geologic regions, which meant that 10 soil units were considered. Five classes of management techniques were identified [7], differing mainly in terms of sowing techniques 
(sowing stick, horse-drawn or tractor-drawn sowing machine). Fields sown with a sowing stick were not fertilized. Two fertilization levels were distinguished in the other cases. Soil was prepared using two light diskings, a deep one $(15 \mathrm{~cm})$ followed by a superficial one. Weeding was performed with a horsedrawn cultivator, plus manual hoeing. Harvest was manual.

\subsection{Initial model}

The Stics [12] model was chosen as the initial model. It estimates daily values for total aboveground biomass, leaf area index, vertical root density distribution and grain yield of a maize crop sown at any plant density and subject to water and nitrogen constraints. Therefore $\mathrm{D}, \mathrm{W}$, and $\mathrm{N}$ were accounted for by Stics (they are hereafter referred to as "modeled constraints"), whereas the other constraints P, K, A, H, OB and X (Tab. I) were ignored by this model (they are "extra constraints" relative to Stics). Stics was built using classical and robust approaches such as the thermal time control of phenological stages, Beer's law for radiation interception, the radiation use efficiency concept, the use of the harvest index for partitioning biomass into grain, and the reservoir analogy for soil water balance. It is structured so that each main process considered is simulated by a specific module. This was expected to facilitate the incorporation of modules accounting for new constraints. Stics was calibrated and validated (Fig. 2) prior to the work reported in the present article for the conditions encountered in Silvânia [3]. The model error was assessed according to [31], by an analysis of the relative deviations between observed and simulated yields and leaf area index at flowering. These provided estimates of the confidence intervals for the simulations. The upper limits of confidence at a $99 \%$ level, expressed in relative deviation, were 0.18 and 0.17 , respectively, for simulated yield $\left(\mathrm{Y}_{\mathrm{DWN}}\right)$

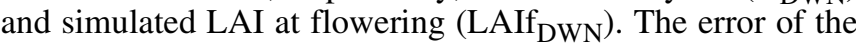
initial model was hereafter assumed to be at most $20 \%$ for both LAIf $_{\text {DWN }}$ and $\mathrm{Y}_{\mathrm{DWN}}$.

\subsection{Structure of the on-farm device}

A survey device was built to represent the local diversity in cropping conditions. It involved the fields of 28 farms across the region. Farmers' field area ranged between 0.5 and 5 ha. Due to the high intra-field heterogeneity of the environment and of the techniques applied by farmers, small plots were chosen as the elementary unit of the survey (crop situation). The area of the plots, $25 \mathrm{~m}^{2}$, was a compromise between the objective of maximizing measurement precision for each plot (some of the measurements being destructive) and the objective of minimum intra-plot heterogeneity.

The survey was conducted over three growing seasons (1994-95 to 1996-97). Each season, a set of 50 plots (10 soil units $\times 5$ classes of management techniques) was selected from the fields of the 28 farms. Thus, at the end of the third season of the survey, the overall plot sample comprised 150 plots, or "crop situations" (sample A). These 150 plots included the set of 12 plots used in the preliminary survey, for which soil profiles were obtained. It is worth noting that since many farmers changed their technical practices from one year to the next, the plot sample had to be reconstructed at the a)

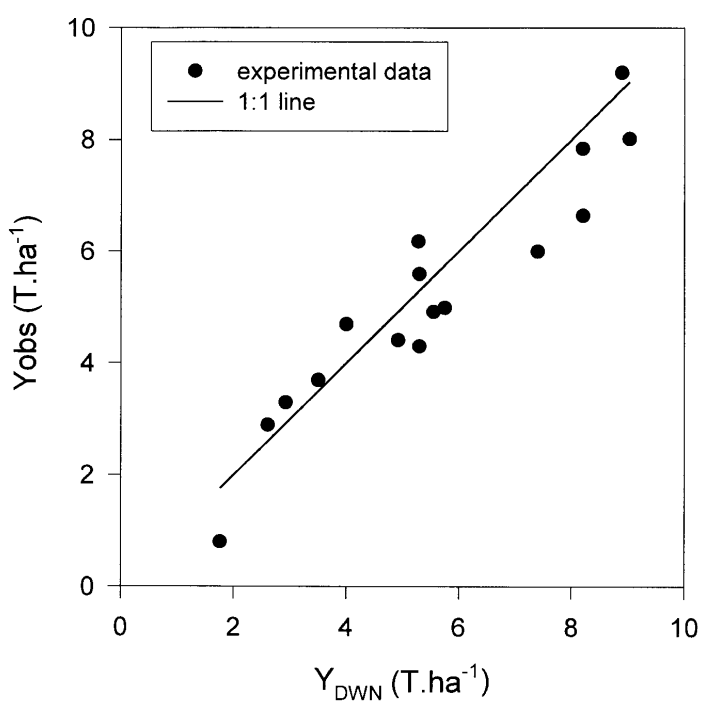

b)

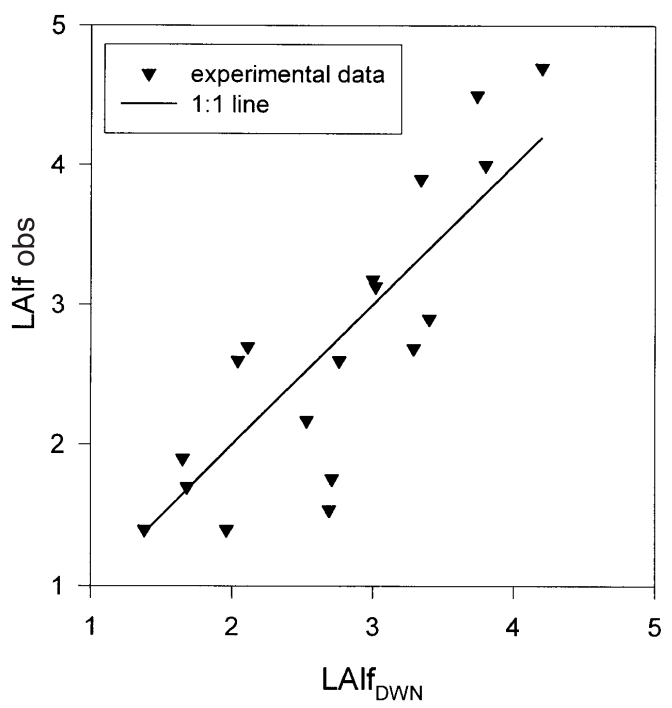

Figure 2. Stics validation as performed prior to the present study [3]. Comparisons between observed (subscript "obs") and simulated (subscript "DWN") yields (a) and Leaf Area Index at flowering (b). Data from specific experimental plots where all possible constraints were at a non-limiting level, except D (low plant density), W (water) and $\mathrm{N}$ (nitrogen) constraints which were at varying levels.

beginning of each growing season. Therefore, the 50 plots used in the different years were not the same each year. The year factor was used as a mean to increase the diversity of the environmental characteristics (other than those of the soil: i.e. climate, pests, etc.) in the device.

\subsection{Measurements performed on the plots and indicators for occurrence of constraints}

The information gathered on each plot of the survey and the measurements performed aimed to record, on one hand, the 
Stics input parameters, and on the other, its main outputs including actual yield, to allow comparisons between simulations and reality. They also aimed to record all the other characteristics of the crop, namely the technical management and the environmental characteristics possibly involved in yield gap, according to the preliminary diagnosis, with reference to the current agronomic knowledge on crop yield building.

Grain yield ( $\left.\mathrm{Y}_{\mathrm{obs}}\right)$ and the number of plants per unit of area at emergence (Npa) were measured on each plot. Leaf area index at flowering ( LAIf $_{\text {obs }}$ ) was indirectly evaluated with a probe (Picqhélios, AERIC S.A.) measuring the radiation extinction for an area of $5 \mathrm{~m}^{2}$, with four repetitions in each plot. The probe was calibrated in the first year of the study with reference to measurements for LAI taken with a LAI-meter (LI3000, LI-COR, measuring the surface area of leaves taken one by one).

Soil samples were collected in each plot at the beginning of each cropping season at 0-20, 20-40, 40-60, 60-80 and 80$100 \mathrm{~cm}$ (4 repetitions were used to build a composite sample for each depth). Laboratory analyses were conducted for texture, soil water retention curves, the cation exchange complex, $\mathrm{pH}(\mathrm{KCl})$, total $\mathrm{N}$, available $\mathrm{P}$ (Bray-I), and total organic matter. The soil water retention curves were obtained by centrifugation (standard routine at the EMBRAPA-CPAC soil laboratory) for all soil samples. Additionally, both drilled and non-deformed samples were simultaneously taken from adjacent points in the 12 pits dug in the preliminary survey. Retention curves were obtained using a pressure blade for non-deformed samples, while the curves for the other samples were obtained using the centrifugation method. This was done in order to assess, relative to the most precise protocol which could not be routinely used (non-deformed samples + pressure blade), the error associated with the protocol used in the survey (drilled sample + centrifugation). Similarly, chemical analyses were applied to the two kinds of soil samples. For the 12 plots studied in the preliminary survey, and also included in the detailed survey, maximum root depth was observed as the depth of the deepest root detected visually at flowering, after softly cleaning the profile with a small knife (the profiles were $120 \mathrm{~cm}$ wide and $200 \mathrm{~cm}$ deep).

At 10, 30, 60, 90 and 130 days after sowing, the three predominant weed species, weed infestation level, and disease/pest damage (using a five-level scale in both cases) were recorded for all plots. Dates and descriptions of all management operations were also recorded, as well as the dates of the main phenological stages.

Solar radiation, temperature, wind velocity and air moisture were recorded at a central location in the Silvânia region by an automatic weather station (Cimel Electronique, Paris). Precipitation was measured daily with gauges located on each of the 28 farms taking part in the study.

The methodology of [18] requires that the environmental conditions possibly responsible for yield-limiting constraints should be evaluated with indicators. These indicators are built from the data recorded in the survey, according to the available knowledge regarding the effects the suspected constraints may have on the crop under study. These indicators do not offer information on the extent to which growth is constrained by the environment. Rather, they aim to characterize the environment by distinguishing two cases for each group of environmental characteristics related to a particular constraint: the case in which it can be assumed that these characteristics do not constrain growth, and the case in which these characteristics are possibly constraining. In our study, however, such indicators were required only for extra constraints, since Stics was already able to provide a more complete picture of the environmental characteristics related to the modeled constraints $\mathrm{D}, \mathrm{W}$ and $\mathrm{N}$, by predicting their effects on growth. The "extra-constraint indicators" are defined in Table II according to the following: aluminum toxicity is known to be correctly assessed by the Al saturation rate of the cation exchange capacity $[1,10,11,34]$, and maize root growth of most cultivars used in Brazil is constrained when the rate exceeds $45 \%$ [21]. Ca deficiency in soil has similar effects on root growth when Ca concentration is below $0.05 \mathrm{meq} / 100 \mathrm{~g}[15,36]$. Weed infestation, insect attacks and diseases, as evaluated using the five-level scale mentioned above, were assumed to have a higher impact on yield when occurring during the pre-flowering stages, than when occurring afterwards. Water excess was assessed using the Stics water balance module, considering that simulated drainage below the root zone indicates that the entire root zone is water-saturated immediately after the rain causing this drainage. Given the soil's relatively high hydraulic conductivity, however, gravitational water is drained away within a few hours following rain in the soils present at Silvânia. The water excess constraint is thus likely (and supposed) to be low when such drainage occurs sporadically. On the other hand, periods of consecutive days of rainfall exceeding the soil's storage capacity were supposed to provoke anoxia in the root zone. $\mathrm{P}$ and $\mathrm{K}$ contents in the soil were considered to be constraining when below thresholds given by [20] and [42]. Lastly, P and K fertilizer amounts used by Silvânia farmers were classified into four classes, defined so that the number of plots in each class was constant.

Due to inevitable difficulties involved in the on-farm monitoring of a set of plots spread over a relatively large area, some data was missing at the end of the survey. Six plots were harvested by their owners before we could measure the yield components. Some of the dates of the technical operations such as tillage, weeding and fertilization, which should have been recorded by the farmers, were also lost. As LAIf measurements had to be performed under a clear sky with the sun at zenith, they were only obtained for 92 plots. Three subsamples of plots were built up and care was taken to ensure that they were representative of the different crop situations. The first one (112 plots, sample B) was complete except for LAIf $_{\text {obs }}$, dates of fertilizer application, dates of weeding and tillage, and soil chemical analysis for the 40-100 cm layer. The second sample (86 plots, sample C) was taken from sample B, with no missing data for LAIf $_{\text {obs }}$ and fertilizer application dates. The third sample included 54 plots (sample D) with the full set of monitored variables, with no missing data except for LAIf obs $_{\text {. }}$.

\subsection{Methodology of Stage I}

For a given plot, the deviation $\left(\mathrm{Y}_{\mathrm{DWN}}-\mathrm{Y}_{\mathrm{obs}}\right)$ between the yield simulated by Stics and the observed one ("overall error") 
Table II. Extra constraint indicators (defined at Stage 0 for use at Stage I).

\begin{tabular}{|c|c|c|c|}
\hline $\begin{array}{l}\text { Extra constraint }^{(1)} \\
\text { abbreviation }\end{array}$ & Constraint & Indicator building & $\begin{array}{l}\text { Classification criteria used for defining the } \\
\text { level of each extra-constraint indicator as } \\
\text { "possibly constraining yield" }\end{array}$ \\
\hline $\mathrm{A}$ & $\begin{array}{l}\text { Al constraint/ } \mathrm{Ca} \\
\text { deficiency }\end{array}$ & $\begin{array}{l}\text { Initial soil depth (from surface to } 100 \mathrm{~cm} \text { ) at } \\
\text { which } \mathrm{Al} \text { saturation exceeds } 45 \% \text { or } \mathrm{Ca} \text { is } \\
\text { lower than } 0.05 \mathrm{meq} / 100 \mathrm{~g} \text { (one value for the } \\
\text { crop cycle; soil sampling before sowing) }\end{array}$ & $<100 \mathrm{~cm}$ \\
\hline $\begin{array}{l}\mathrm{H}\left(\mathrm{H}_{\text {pre }}, \mathrm{H}_{\text {post }}\right) \\
\text { OB (Other Biotic stress }) \\
\left(\mathrm{OB}_{\text {pre }}, \mathrm{OB}_{\text {post }}\right)\end{array}$ & $\begin{array}{c}\text { Weeds } \\
\text { Diseases } \\
\text { Insect attacks }\end{array}$ & $\begin{array}{l}\text { Visual estimation rated on a } 1 \text { (lowest } \\
\text { infestation) to } 5 \text { (highest infestation) scale at } \\
10,30,60,90 \text {, and } 130 \text { days after sowing }\end{array}$ & $\begin{array}{l}\text { Pre-flowering: rated over } 2 \text { at } 10 \text { or } \\
30 \text { days }\left(\mathrm{H}_{\text {pre }}, \mathrm{OB}_{\text {pre }}\right) \text {; } \\
\text { post-flowering: note over } 3 \text { at } 60,90 \text { or } \\
130 \text { days }\left(\mathrm{H}_{\text {post }}, \mathrm{OB}_{\text {post }}\right)\end{array}$ \\
\hline $\mathrm{X}\left(\mathrm{X}_{\text {pre }}, \mathrm{X}_{\text {post }}\right)$ & Water excess & $\begin{array}{l}\text { Sequences of consecutive days for which } \\
\text { Stics simulated drainage below root zone }\end{array}$ & $\begin{array}{l}3 \text { or more consecutive days. } \\
\text { If occurring before flowering: } X_{\text {pre }} \text {; if } \\
\text { occurring before or after flowering: } \\
X_{\text {post }} \text { (2) }\end{array}$ \\
\hline $\begin{array}{l}\mathrm{P} \\
\text { (defined by combining soil deficiency } \\
\text { with level of } \mathrm{P} \text { fertilization) }\end{array}$ & $\begin{array}{l}\text { P deficiency in soil } \\
\text { P fertilization }\end{array}$ & $\begin{array}{l}\mathrm{P}(\text { Bray I). } 0-20 \mathrm{~cm} \text { soil sample collected } \\
\text { before sowing. } \\
\text { Amounts of } \mathrm{P}_{2} \mathrm{O}_{5} \text { provided by fertilization }\end{array}$ & $\begin{array}{c}\mathrm{P}(\text { Bray } \mathrm{I})<5.5 \mathrm{ppm} \text { and } \mathrm{P} \text { fertilization }< \\
50 \mathrm{~kg} \cdot \mathrm{ha}^{-1}\end{array}$ \\
\hline $\begin{array}{l}\mathrm{K} \\
\text { (same principle as for } \mathrm{P} \text { constraint) }\end{array}$ & $\begin{array}{l}\text { K deficiency in soil } \\
\text { K fertilization }\end{array}$ & $\begin{array}{l}\mathrm{K} \text { concentration in } 0-20 \mathrm{~cm} \text { soil sample } \\
\text { collected before sowing. } \\
\text { Amounts of } \mathrm{K}_{2} \mathrm{O} \text { provided by fertilization } \\
\text { (plot sample divided into } 4 \text { classes) }\end{array}$ & $\begin{array}{c}\mathrm{K}<0.15 \mathrm{meq} / 100 \mathrm{~g} \text { and } \mathrm{K} 2 \mathrm{O} \text { fertilization } \\
\quad<40 \mathrm{~kg} \cdot \mathrm{ha}^{-1}\end{array}$ \\
\hline
\end{tabular}

(1) Applies to all the constraints not accounted for by Stics, among those listed in Table I. Subscripts "pre" and "post", meaning, respectively, "preflowering" and "post-flowering" apply to constraints that may affect growth during a limited part of the cycle, the corresponding indicator being monitored throughout the growing season.

(2) When 3 or more consecutive days of drainage below root zone are simulated, it is assumed that the X constraint is present for the entire remaining part of the growing cycle because it may have affected root depth with possible consequences on above-ground growth at any moment after this event.

was assumed to be the sum of (i) errors due to the fact that the model ignores the extra constraints present in the plots ("extra gap"), and (ii) errors in the simulation of the effects of the modeled constraints (model error). As seen above (Sect. 2.3), the model error was less than $20 \%$. The extra gap is expected to be positive or null because the observed yield is expected to be lower than the yield that would be achieved in the absence of constraints other than the modeled constraints. Hereafter it was assumed that the extra gap was not null if:

$$
\left(\mathrm{Y}_{\mathrm{DWN}}-\mathrm{Y}_{\mathrm{obs}}\right) / \mathrm{Y}_{\mathrm{DWN}}>0.2 \text {. }
$$

Stage I aimed to cross the information provided by the extra gap with the information provided by the extra constraints indicators, in order to identify the extra constraints present in each plot. The probability that at least one extra constraint was present in a plot increases as the extra gap predominates in the overall error of the simulations. However, the extra gap may be null even when extra constraints occurred, due to possible interactions between modeled and extra constraints in the plots. For example, if a pest reduced leaf area before flowering, this may decrease the crop's water requirements to such an extent that no water stress occurs during the remaining part of the cycle, whereas it would have occurred if pest damage had not taken place first. In such a case, the observed yield may be equal to (or even greater than) the yield simulated with Stics, despite the actual occurrence of an extra constraint.

In order to reduce the risk of diagnosis errors in such a case, it was necessary to analyze not only the extra gap, but also the chronology of "extra growth reduction", i.e. the chronology of growth reduction relative to growth simulated by Stics. This was done by using comparisons between simulated and observed LAIf obs $_{\text {, as follows (Fig. 3). When (LAIf }}$ DWN $_{-}$

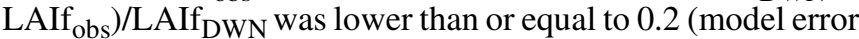
on LAI at flowering), it was assumed that no extra growth reduction had occurred before flowering. In this particular case, $\left(\mathrm{Y}_{\mathrm{DWN}}-\mathrm{Y}_{\mathrm{obs}}\right) / \mathrm{Y}_{\mathrm{obs}}>0.2$ and $\left(\mathrm{Y}_{\mathrm{DWN}}-\mathrm{Y}_{\mathrm{obs}}\right) /$ $\mathrm{Y}_{\mathrm{obs}} \leq 0.2$ were assumed to, respectively, indicate extra growth reduction after flowering and no extra growth reduction. (LAIf $_{\mathrm{DWN}}-\mathrm{LAIf}_{\mathrm{obs}}$ )/LAIf $\mathrm{LWN}_{\mathrm{DWN}}>0.2$ was assumed to indicate extra growth reduction before flowering. In this particular case, however, the occurrence of extra growth reduction after flowering could not be inferred from comparisons between observed and simulated yields as simply as in the preceding case. This is due to the fact that the simulations did not offer information on what crop growth would have been, taking into account the initial growth reduction which resulted in the observed LAIf $_{\text {obs }}$, but assuming that no additional extra-constraint occurred afterwards. This hypothetical trend in crop growth was 


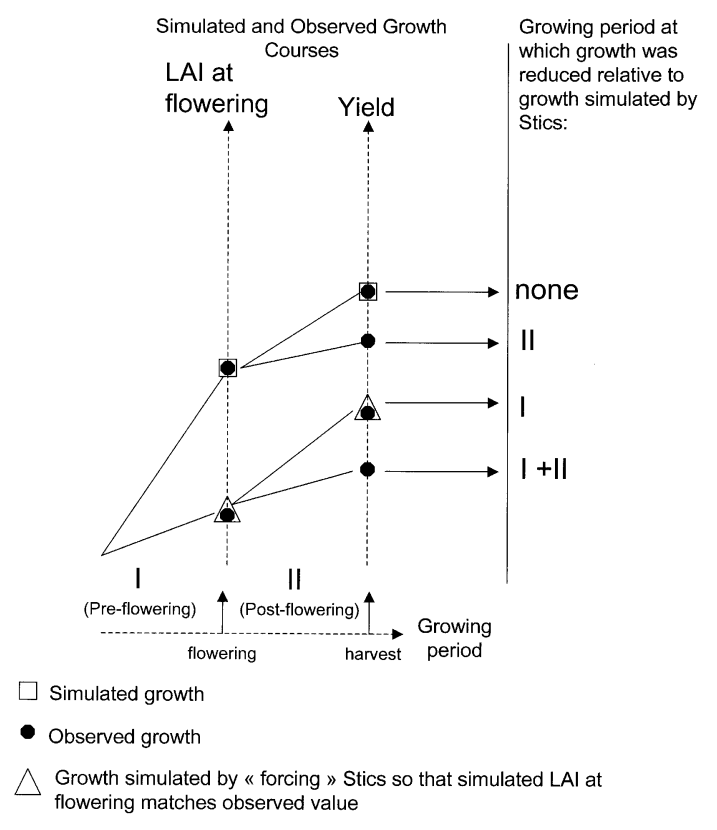

Figure 3. Schematic description of the method for identifying the chronology of "extra-growth" reductions of a plot at Stage I of the analysis. Extra growth reductions are growth reductions relative to the growth simulated by Stics.

approximated by specific simulations in which Stics was "forced" to reach LAIf ${ }_{\text {obs }}$, instead of its normal simulated value. Then, the post-flowering part of the cycle was simulated starting from LAIf ${ }_{\text {obs }}$ and without forcing the model any further. $\left(\mathrm{Y}_{\mathrm{DWN}}{ }^{*}-\mathrm{Y}_{\mathrm{obs}}\right) / \mathrm{Y}_{\mathrm{DWN}}{ }^{*}>0.2$ and $\left(\mathrm{Y}_{\mathrm{DWN}}{ }^{*}-\right.$ $\left.\mathrm{Y}_{\mathrm{obs}}\right) / \mathrm{Y}_{\mathrm{DWN}}{ }^{*} \leq 0.2$ were then, respectively, assumed to indicate extra growth reduction after flowering or no extra growth reduction after flowering, where $Y_{D W N} *$ is the yield obtained by the "forced" simulation described above. Since LAIf $_{\text {obs }}$ was required for this analysis, this was restricted to the sub-sample of 86 plots for which this data was available.

A given extra constraint was assumed to occur in a given plot if and only if:

(i) the corresponding extra constraint indicator was at a limiting level as defined in Table II, and,

(ii) the chronology of growth reduction for the plot was consistent with the date at which the indicator reached a limiting value and with the following assumptions made about the effects of the extra constraints: $\mathrm{P}$ and $\mathrm{K}$ constraints have long-lasting effects on growth, starting before flowering; the $\mathrm{Al} / \mathrm{Ca}$ constraint may limit growth at any stage (its effect depends on water stress because it affects root depth); water excess, besides decreasing root growth rate, may affect growth at any period after its occurrence (there is an interaction between root growth reduction and water stress).

Once we established, for each extra constraint, whether it occurred or not in each plot, the final step of Stage I consisted of studying how the extra-constraints were combined in the plots.

Therefore, Stage I was expected to provide: (i) an estimate of the extra gap for each plot; (ii) the list of extra constraints occurring in each plot, and (iii) the hierarchy of the extra constraints in terms of their frequency of occurrence, expressed by the proportion of plots of the survey in which a given constraint was found to limit yield.

\subsection{Methodology of Stage II}

In Stage II, the extra constraints identified during Stage I, as those occurring most frequently or as producing the strongest effects on growth, were introduced into the model (they became modeled constraints, while the other constraints remained extra constraints relative to the new model) using the available knowledge on the way they limit yield and interact with technical management and the environment. The validity of the new functions added to the model was not intended to go beyond the specific context studied, nor was it intended that the modified model would be the "ideal" model for this context. Nevertheless, the modeling attempted to account for a minimum level of complexity needed to simulate the effects of each newly modeled constraint in the local context. This corresponds to ad hoc modeling, according to Sinclair and Seligman [40]. The choice and the fitting of a function describing the effects of each newly modeled constraint resulted from a trial-and-error calibration strategy. It started from the simplest approach described in the literature, such as a linear relationship between final yield and the level of a constraint, as assessed by its corresponding indicator. Greater complexity was progressively introduced whenever the function chosen in the preceding step failed to adequately simulate the yields of a set of plots extracted from the survey. For each constraint to be modeled, the plots were selected aiming at a maximum contrast in terms of level and dynamics of both the studied extra constraint and the constraints already present in Stics (W, D and N). The quality of the simulations was assessed with the square sum of the deviations between the simulated and observed yields. Only the final results of this iterative modeling process are reported in this paper. Nevertheless, interested readers may refer to [3] for more details on the intermediary steps, to obtain a more objective justification of the final modeling choices. A partial validation of the new overall model (Stics-modified) was finally done also using data from the survey, including data used for the calibration of each new function. Validation obtained from an independent set of data would be required for further application. The partial validation aimed to provide an error estimate of the model and attempted to ensure that error was not due to the occurrence of constraints still ignored by the final model among those monitored in the survey.

Therefore, at the end of this Stage II, the constraints ignored by the model were assumed to have an insignificant influence on local yields.

\subsection{Methodology of Stage III}

Finally, a third Stage (III) aimed to refine the hierarchy of the causes of yield gap in the studied region by (i) quantifying better their respective impact on yield, and (ii) by identifying, among these causes, those resulting from environmental characteristics and those that were especially dependent on the technical management. 
The general principle was to conduct a sensitivity analysis of Stics-modified. However, this was not done by systematically varying the value of key input variables starting from a single reference situation, as is often done to test a model. In our case, the objective was to evaluate the extent and frequency the input variables affected the simulated yields of the plots in the survey. Hence, for each plot, the variation of each input variable considered two levels only: the level measured in the plot and a reference level. The latter level was a non-limiting level whenever applicable (e.g. nitrogen fertilization or rainfall exceeding crop demand, $200 \mathrm{~cm}$ soil depth, assumed to be non-limiting for maize root expansion, etc.) or the less limiting level observed in the region (e.g. maximum observed value for soil available water capacity) in the case of variables for which a non-limiting level could not be defined. For each actual plot of the survey, a "virtual experiment" could be designed, in which the tested factors were the input variables with their two levels as defined above. However, a huge combinatory space would have been required to test all the interactions between input variables, given the number of input variables of Stics (over 50) and of its modified version as well. Alternatively, according to the screening technique described by Coquillard and Hill [13], this space was explored progressively. The input variables were aggregated according to the constraint in which they were involved in Stics-modified, for it was possible to define the group of variables involved in the calculation of the water constraint, the group of variables involved in the calculation of the nitrogen constraint, etc. Thus, the study first focused on the sensitivity of the model for each of the modeled constraints. The study of the influence of each input variable was then restricted to the variables involved in those constraints that showed a dominating influence on simulation results. The influence of the other variables was ignored. Hence, a first "virtual experiment" was designed in order to compare the following hypothetical yields:

- $\mathrm{Y}_{0}$ : the simulated yield for a given cultivar and sowing date, that would have been harvested in the plot in the absence of limiting factors other than radiation and temperature. $\mathrm{Y}_{0}$ defines what is hereafter named the simulated potential yield;

- $\mathrm{Y}_{\mathrm{c}}$ : the simulated yield obtained if the modeled constraint $\mathrm{c}$ had been the only constraint limiting yield beyond those involved in $\mathrm{Y}_{0}$, among all other possible constraints: input variables related to constraint $\mathrm{c}$ were given observed values, while all the other input variables were given reference values;

- $\mathrm{Y}_{\mathrm{c}_{1} \mathrm{c}_{2}}$ : the simulated yield obtained if only the modeled constraints $\mathrm{c}_{1}$ and $\mathrm{c}_{2}$ reduced the yield;

- $\mathrm{Y}_{\mathrm{c}_{1} \ldots \mathrm{c}_{\mathrm{k}}}$ : the simulated yield obtained if the modeled constraints $c_{1}, c_{2} \ldots$ to $\mathrm{C}_{\mathrm{k}}$ reduced yield, with $\mathrm{k} \leq \mathrm{n}$ and $\mathrm{n}$ being the total number of modeled constraints in Stics-modified.

It is then possible to calculate the relative simulated yield gaps $G_{c_{i}}$ and $G_{c_{1} \ldots c_{k}}$ that would have occurred if a single constraint $c_{i}$, and more generally, a given set of modeled constraints $c_{1} \ldots c_{k}$ were the only cause of yield reduction beyond radiation and temperature:

$$
\mathrm{G}_{\mathrm{c}_{\mathrm{i}}}=1-\mathrm{Y}_{\mathrm{c}_{\mathrm{i}}} / \mathrm{Y}_{0}
$$

$$
\mathrm{G}_{\mathrm{c}_{1} \ldots \mathrm{c}_{\mathrm{k}}}=1-\mathrm{Y}_{\mathrm{c}_{1} \ldots \mathrm{c}_{\mathrm{k}}} / \mathrm{Y}_{0}
$$

The role of the interactions between modeled constraints was also quantified. As in ANOVA, interaction between constraints was assumed to occur when the effect of one constraint depended on the level of the others. In such a case, the effects of the two modeled constraints involved are not simply cumulative. The two-way interaction $I_{c_{1}} c_{2}$ between two constraints $c_{1}$ and $c_{2}$ is:

$$
\mathrm{I}_{\mathrm{c}_{1} \mathrm{c}_{2}}=\mathrm{G}_{\mathrm{c}_{1} \mathrm{c}_{2}}-\left(\mathrm{G}_{\mathrm{c}_{1}}+\mathrm{G}_{\mathrm{c}_{2}}\right) \text {. }
$$

Higher order interactions were calculated according to the same principles. For the three constraints $c_{1}, c_{2}$ and $c_{3}, I_{c_{1} c_{2}}$, $\mathrm{I}_{\mathrm{c}_{1} \mathrm{c}_{3}}$ and $\mathrm{I}_{\mathrm{c}_{2} \mathrm{c}_{3}}$ were calculated as above, $\mathrm{I}_{\mathrm{c}_{1} \mathrm{c}_{2} \mathrm{c}_{3}}$ being calculated as follows:

$$
I_{c_{1} c_{2} c_{3}}=G_{c_{1} c_{2} c_{3}}-\left(G_{c_{1}}+G_{c_{2}}+G_{c_{3}}\right)-I_{c_{1} c_{2}}-I_{c_{1} c_{3}}-I_{c_{2} c_{3}} \cdot(5)
$$

The number of simulations required for the calculation of all the simulated contributions offered by modeled constraints to the simulated yield gap, including their interactions, is expected to be:

$$
\mathrm{N}=\mathrm{p} \cdot 2^{\mathrm{n}}
$$

where $\mathrm{p}$ is the number of plots of the survey in the sample used and $\mathrm{n}$ the number of modeled constraints (two levels are considered for each constraint in each plot: absence of the constraint, and presence at the level determined by the observed values of the input variables linked to the constraint).

The interaction of a given set of constraints is positive when it aggravates the yield reduction as compared with the sum of their main effects. It is negative when it leads to lower yield reductions. A given interaction between constraints may be negative or positive depending on the individual cropping situation. In the discussion of the results, we will consider plots with a positive interaction value separately from those with a negative value (the corresponding mean values are calculated separately to differentiate between these two cases when they occur).

The only available error measurement for Stics-modified is the deviation between $\mathrm{Y}_{0}$ and simulated yield $\mathrm{Y}_{\mathrm{c}_{1} \ldots \mathrm{c}}$, as obtained in the partial validation of Stage II. Since the precision of the simulations was likely to depend on the constraints considered, the errors associated with $\mathrm{G}_{\mathrm{c}_{1} \ldots \mathrm{c}_{\mathrm{k}}}$ and $\mathrm{I}_{\mathrm{c}_{1} \ldots \mathrm{c}_{\mathrm{k}}}$ where $c_{1} \ldots c_{k}$ is a subset of the modeled constraints, were actually unknown. This is presently one of the main limits of the method, being inherent in the on-farm diagnosis purpose, since estimating these errors would require an experimental device designed to allow an analysis of variance of $Y_{c_{1} \ldots c_{n}}$ with $c_{1} \ldots c_{n}$ as "treatments", which would certainly not take place in an on-farm context. It may be reasonably assumed, however, that the effects measured by $G$ and I are not significant when their values are lower than the error of the overall model.

For each modeled constraint whose role in the yield gap could not be ignored according to the above criteria, the sensitivity analysis was then refined. The influence of the input variables involved in the simulation of each of these constraints was assessed with the same type of procedure as 
the one used for the constraints themselves. For example, if simulated water stress had a strong impact on simulated yields in the studied region, the sensitivity analysis had to focus on the response of the simulated yield to rainfall, soil water storage capacity, runoff, plant water requirements, etc., taking into account the actual variation interval for each of these variables in the Silvânia region. However, the number of variables to be tested was too high to allow an assessment of the full set of interactions between variables. Thus, the input variables were considered stepwise, starting from a hypothetical crop situation where only one variable was at its observed level, all the others being given reference values (non-limiting whenever applicable, otherwise the less limiting value observed in the entire survey was used, as it was for the study at the constraint level). These were then introduced one by one as observed values in the model, giving access to cumulated interactions only, some lower order interactions being ignored.

At the end of this stage, further diagnosis may still be required if some of the model's input variables do not directly characterize technical interventions by farmers or a given environmental aspect. This would be the case, for example, of plant density at emergence. This is a Stics input variable, but it may result from interactions between numerous technical management characteristics on one hand, such as soil tillage and sowing, and various environmental aspects, such as soil water status at sowing, rainfall and pests between sowing and emergence, physical structure of the seed bed, etc., on the other. Thus, whenever the analysis conducted from Stage I to Stage III indicated that plant density at emergence strongly limited yields in the region, the respective influences of these technical and environmental aspects still needed to be studied, should the overall diagnosis study result in technical recommendations to farmers. Although this important final stage of the diagnosis was actually performed in Silvânia [3] following the methodology of [18], it is not presented in this paper because the scope of its results is only local.

Indeed, the study actually performed in Silvânia involved many aspects that provided information of little interest outside this locality. This information was not reported in the present paper, in order to concentrate on aspects that we considered possibly more innovative. In some cases, when results of the parts omitted were necessary for understanding the general results, they are cited in the article without presenting supporting data and with the mention "data not shown". Interested readers may refer to [3] for a fully detailed report of the overall study.

\section{RESULTS}

\subsection{First diagnosis of extra constraints (Stage I)}

As shown in Figure 4, there was a large remaining variability in the difference between simulated yield $\mathrm{Y}_{\mathrm{DWN}}$ and $\mathrm{Y}_{\mathrm{obs}}$ (sub-sample B of 112 plots). For most plots, the deviation between $\mathrm{Y}_{\mathrm{DWN}}$ and $\mathrm{Y}_{\mathrm{obs}}$ was markedly greater than the $20 \%$ error of Stics, which means that the gap unequivocally resulted from constraints not accounted for by Stics.

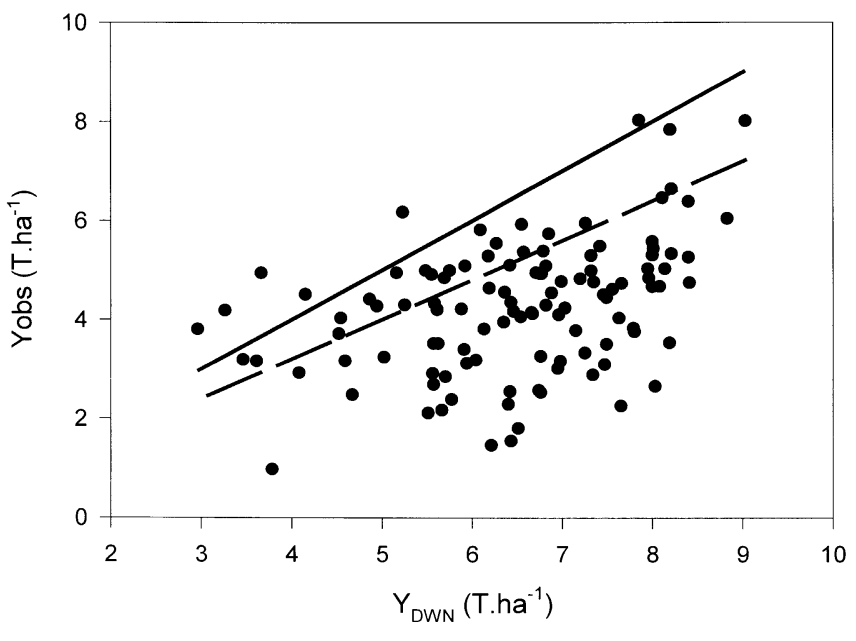

Figure 4. Relation between observed yields $\left(\mathrm{Y}_{\mathrm{obs}}\right)$ and yields resulting from the effects of $\mathrm{D}, \mathrm{W}$ and $\mathrm{N}$ (see caption of Fig. 2) constraints only $\left(\mathrm{Y}_{\mathrm{DWN}}\right)$, as simulated by Stics. Stage I of the analysis, sample B of 112 plots. Solid line: $\mathrm{Y}=\mathrm{X}$ line; dashed line: $\mathrm{Y}=0.8 \mathrm{X}$ line. Given a $20 \%$ error for Stics, observed yields below this line ("extra gap" + model error $>0.2$ ) can be assumed to result not only from the limitations predicted by Stics but also from additional limitations not accounted for by this model (due to "extra constraints").

Table III shows the distribution of the plots (sub-sample C, of 86 plots, for which this analysis was practicable) according to their chronology of extra growth reduction relative to growth simulated with Stics. Only $15 \%$ of the plots were shown to be free of any extra constraints (profile \#1). In onethird of the plots, growth was affected by extra constraints throughout the growing cycle (profile \#4). The frequency of occurrence of each extra constraint was calculated as the frequency of the plots of sub-sample $\mathrm{C}$ in which the corresponding extra constraint indicator reached a high level (according to Tab. II), while being consistent with the chronology of growth reduction. The most frequent extra constraints were, in decreasing order, A, H and X (Fig. 5).

In many plots, several extra constraints were simultaneously present. Table IV shows the distribution of the plots in the distinct combinations of extra-constraints that were identified and the mean extra growth reduction for each combination, distinguishing between the pre-flowering (Tab. IVa) and post-flowering (Tab. IVb) periods. The results presented in Table IV suggest that none of the extra-constraints were predominant as a cause of extra growth reduction. However, the great number of distinct combinations of extra constraints and the resulting low number of plots subject to each of these combinations prohibited the assessment of reliable estimates of the effect of the extra-constraints on yield. Hence a direct analysis of the role played by each extra constraint in local extra growth reductions was not possible.

Thus, at this stage of the diagnosis we could not establish a hierarchy of the extra constraints in terms of their impact on yield, but only in terms of their frequency of occurrence.

It was decided that an improvement of Stics was needed in order to account for the three most frequent extra constraints 
Table III. Distribution of the plots according to their chronology of growth reduction relative to simulated growth. Stage I of the analysis.

\begin{tabular}{|c|c|c|c|c|c|}
\hline \multirow[b]{2}{*}{ Profile number } & \multicolumn{2}{|c|}{ Criterion defining profile of growth reduction } & \multicolumn{2}{|c|}{$\begin{array}{l}\text { Period during which growth reduction occurred } \\
\text { (relative to growth simulated with Stics) }\end{array}$} & \multirow[b]{2}{*}{$\%$ of plots } \\
\hline & $\left(\mathrm{LAIf}_{\mathrm{DWN}}-\mathrm{LAIf}_{\mathrm{obs}}\right) / \mathrm{LAIf}_{\mathrm{DWN}}$ & $\left(\mathrm{Y}_{\mathrm{DWN}}{ }^{*}-\mathrm{Y}_{\mathrm{obs}}\right) / \mathrm{Y}_{\mathrm{DWN}}{ }^{*}$ & Emergence to flowering & Flowering to maturity & \\
\hline 1 & $\leq 0.2$ & $\leq 0.2$ & False & False & 15 \\
\hline 2 & $\leq 0.2$ & $>0.2$ & False & True & 27 \\
\hline 3 & $>0.2$ & $\leq 0.2$ & True & False & 25 \\
\hline 4 & $>0.2$ & $>0.2$ & True & True & 33 \\
\hline
\end{tabular}

Sub-sample $\mathrm{C}$ of 86 plots. LAIf ${ }_{\mathrm{DWN}}$ : LAI at flowering simulated by Stics (i.e. taking account $\mathrm{D}, \mathrm{W}$ and $\mathrm{N}$ constraints); LAIf ${ }_{\mathrm{obs}}$ : observed LAI at flowering; $\mathrm{Y}_{\mathrm{DWN}}{ }^{*}$ : Yield simulated by Stics "forced" so that $\mathrm{LAIf}_{\mathrm{DWN}}=\mathrm{LAIf}_{\mathrm{obs}} ; \mathrm{Y}_{\mathrm{obs}}$ : observed yield.

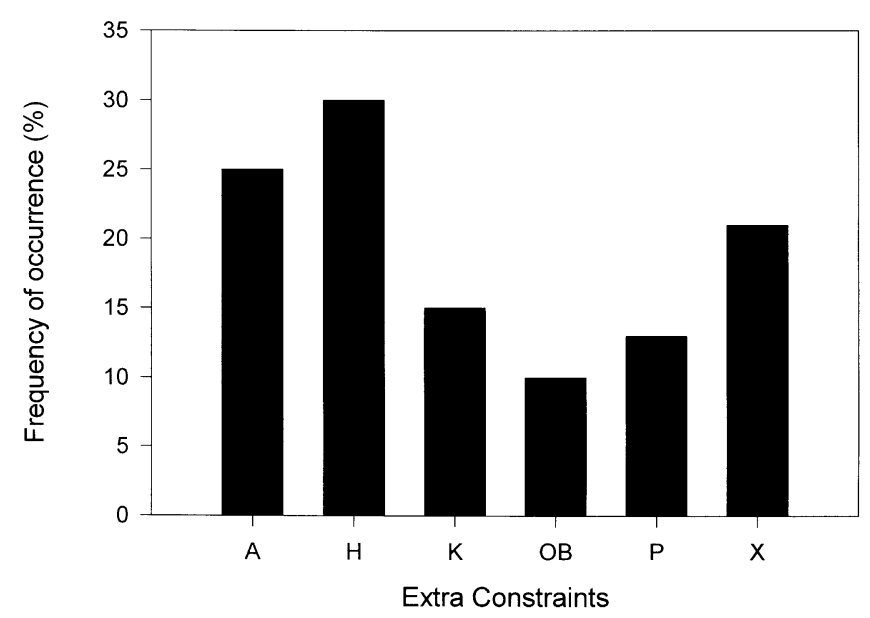

Figure 5. Hierarchy of extra constraints in terms of frequency of occurrence. Stage I of the analysis. Sub-sample C of 86 plots. See Table I for definition of symbols A, H, K, OB, P, and X.

only, which were, as presented above (Fig. 5), weeds, $\mathrm{Al} / \mathrm{Ca}$ and the water excess constraints. According to the methodology described for Stage III, this would allow an assessment of the impact of constraints D, W and $\mathrm{N}$ (already modeled in Stics) and $\mathrm{A}, \mathrm{H}$ and $\mathrm{X}$ (constraints to be modeled in the forthcoming Stage II). This would be done through simulations of $\mathrm{Y}_{\text {DWNAXH }}$ as well as of $\mathrm{Y}_{0}, \mathrm{Y}_{\mathrm{D}}, \mathrm{Y}_{\mathrm{W}}, \mathrm{Y}_{\mathrm{N}}, \mathrm{Y}_{\mathrm{A}}, \mathrm{Y}_{\mathrm{X}}, \mathrm{Y}_{\mathrm{H}}, \mathrm{Y}_{\mathrm{DW}}$, $\mathrm{Y}_{\mathrm{DN}}$, etc. where the subscripts indicate the constraints taken into account in the simulation $\left(\mathrm{Y}_{0}\right.$ represents the case where all the constraints are absent). Since there are 6 constraints to be considered and two levels for each constraint (present or absent), this would require $2^{6}$ simulations for each plot.

\subsection{Stage II: modeling}

By modifying existing functions of Stics or introducing new modules, a new model was built, hereafter named "Stics-modified".

\subsubsection{Al/Ca and water excess constraints in Stics-modified}

It was possible to address the $\mathrm{Al} / \mathrm{Ca}(\mathrm{A})$ and water excess (X) constraints with simple modeling. In accordance with the literature $[15,21,36,39]$, it was assumed that maximum root depth (one of Stics' input data) was limited by the first layer where the $\mathrm{Al}$ saturation rate exceeded $45 \%$ or the $\mathrm{Ca}$ content was below $0.05 \mathrm{meq} / 100 \mathrm{~g}$. The effect of water excess was also taken to occur essentially through a reduction in root growth due to anoxic conditions in the rooting front [28]. Thus water excess was accounted for based on a constant decrease in root growth for each day that the soil is saturated at rooting front depth. However, an explicit simulation of soil saturation would have meant important modifications to the water balance module of Stics. Therefore, it was assumed that saturation occurs in a given layer when it is at field capacity and water is draining down from the upper layer. The water excess function introduced into the water balance module was calibrated with two plots, among those where the root depth had been recorded, where the maximum root depth at flowering was $65 \mathrm{~cm}$ and $105 \mathrm{~cm}$, and where the physical and chemical characteristics of the soils (data not shown) could not be suspected to be responsible for such limited root depth.

\subsubsection{Weeds constraint in Stics-modified}

The weeds $(\mathrm{H})$ constraint was incorporated into Sticsmodified in a more complex way which required the introduction of a new module in Stics.

Several authors, such as Cousens [14] and Wilkerson et al. [45], used regression models in which the final yield is reduced by weeds, as a function of variables such as weeding dates, seed bank in the soil, etc. However, the following multiple, interacting causes of weed pressure were suspected in our case: - high variability of plant density (ranging from 1.88 to 7.72 plants $\cdot \mathrm{m}^{-2}$; mean $=4.15$ plants $\cdot \mathrm{m}^{-2}$, coefficient of variation $=29 \%$ ) and of LAIf $_{\text {obs }}$ (ranging from 0.6 to 3.8; mean $=2.1 ; \mathrm{CV}=35 \%$ ) suggesting a high variability of the radiation available for weeds;

- the time interval between the last disk cultivation and sowing also varied between plots and was frequently long (ranging from 0 to 20 days), which could be suspected to favor weed infestation before maize sowing;

- questioned about the causes of high weed infestation in their fields, some farmers also mentioned the failure of weed control because of adverse climatic conditions.

Therefore, a static approach, as mentioned above, would have been ineffective. Most of the process-oriented, dynamic models described in the literature [22, 24, 25, 44] were designed to take into account the weed-crop interactions for a wide range of environments. However, the use of these models 
Table IV. Distinct combinations of extra constraint occurrences in the plots of the survey and their corresponding mean extra growth reductions, according to the growing period (Stage I of the analysis, Sub-sample C of 86 plots).

(a) Pre-flowering period

Extra-constraints occurring

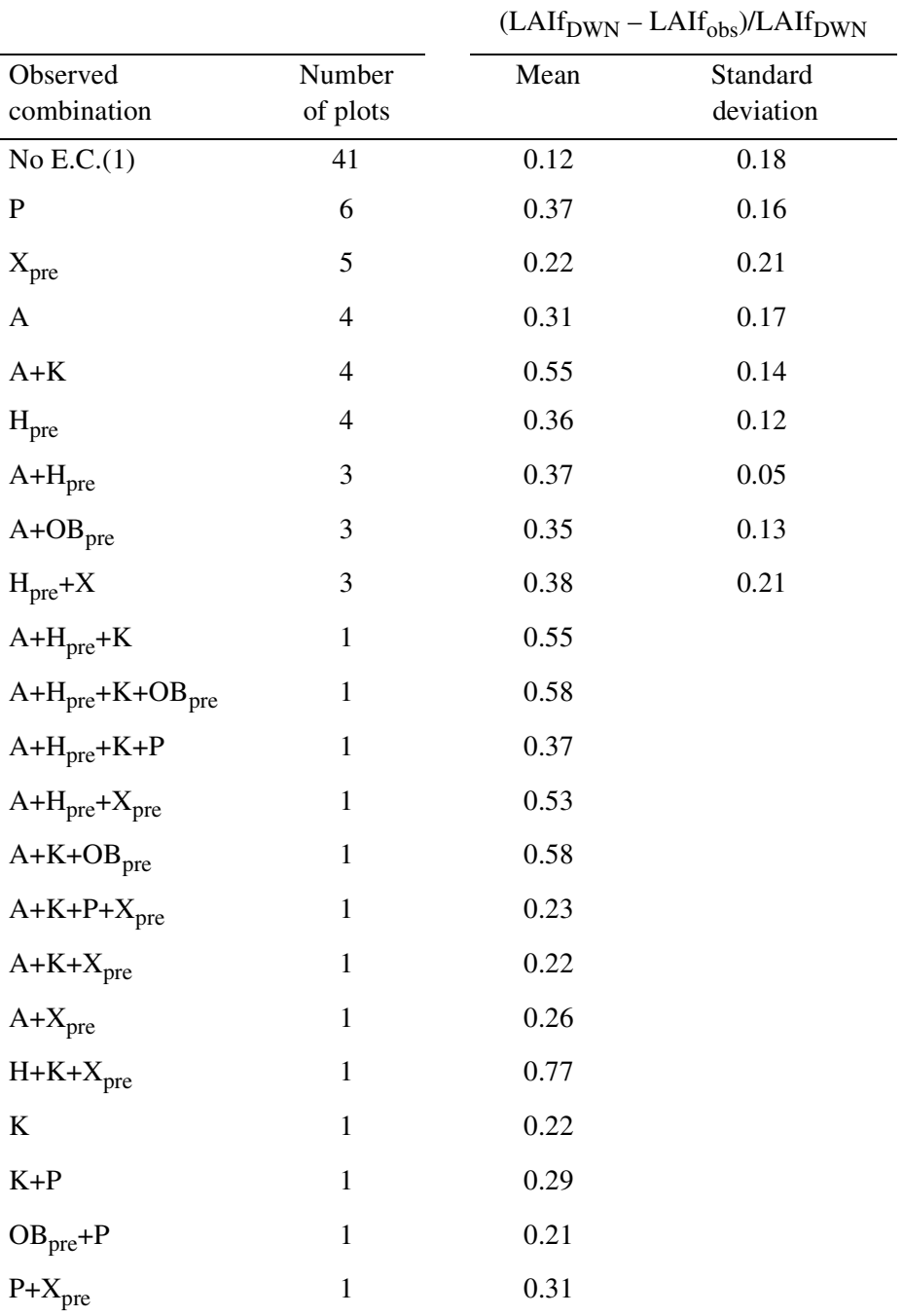

(b) Post-flowering period

Extra constraints occurring

\begin{tabular}{ll}
\hline $\begin{array}{l}\text { Observed } \\
\text { combination }\end{array}$ & $\begin{array}{c}\text { Number } \\
\text { of plots }\end{array}$ \\
\hline
\end{tabular}

Extra growth reduction

\begin{tabular}{|c|c|c|c|}
\hline No E.C.(1) & 34 & 0.22 & 0.20 \\
\hline $\mathrm{H}_{\text {post }}$ & 8 & 0.30 & 0.14 \\
\hline $\mathrm{P}$ & 7 & 0.20 & 0.12 \\
\hline$X_{\text {post }}$ & 6 & 0.07 & 0.17 \\
\hline A & 5 & 0.20 & 0.30 \\
\hline $\mathrm{A}+\mathrm{H}_{\text {post }}$ & 3 & 0.56 & 0.14 \\
\hline$A+K$ & 3 & 0.17 & 0.31 \\
\hline $\mathrm{H}_{\text {post }}+\mathrm{X}_{\text {post }}$ & 3 & 0.36 & 0.04 \\
\hline $\mathrm{A}+\mathrm{H}_{\text {post }}+\mathrm{K}$ & 2 & 0.57 & 0.17 \\
\hline $\mathrm{A}+\mathrm{H}_{\text {post }}+\mathrm{X}_{\text {post }}$ & 2 & 0.32 & 0.18 \\
\hline $\mathrm{A}+\mathrm{K}+\mathrm{X}_{\text {post }}$ & 2 & 0.47 & 0.01 \\
\hline $\mathrm{OB}_{\text {post }}$ & 2 & 0.40 & 0.02 \\
\hline $\mathrm{A}+\mathrm{H}_{\text {post }}+\mathrm{K}+\mathrm{P}$ & 1 & 0.43 & \\
\hline $\mathrm{A}+\mathrm{H}_{\text {post }}+\mathrm{K}+\mathrm{X}_{\text {post }}$ & 1 & 0.70 & \\
\hline $\mathrm{A}+\mathrm{K}+\mathrm{P}+\mathrm{X}_{\text {post }}$ & 1 & 0.52 & \\
\hline $\mathrm{A}+\mathrm{OB}_{\text {post }}$ & 1 & 0.25 & \\
\hline $\mathrm{A}+\mathrm{X}_{\text {post }}$ & 1 & 0.28 & \\
\hline $\mathrm{H}_{\text {post }}+\mathrm{K}+\mathrm{OB}_{\text {post }}$ & 1 & -0.20 & \\
\hline $\mathrm{H}_{\text {post }}+\mathrm{K}+\mathrm{X}_{\text {post }}$ & 1 & 0.34 & \\
\hline $\mathrm{H}_{\text {post }}+\mathrm{P}+\mathrm{X}_{\text {post }}$ & 1 & 0.61 & \\
\hline $\mathrm{K}+\mathrm{P}$ & 1 & 0.25 & \\
\hline
\end{tabular}

(1) No E.C.: no extra constraint recorded during the growing period considered. Extra constraint abbreviations are defined in Table II. An extra constraint was assumed present in a plot when its level was "possibly constraining" according to its indicator (defined in Tab. II). LAIf DWN: LAI at flowering simulated by Stics (i.e. taking into account D, W and N constraints); LAIf ${ }_{\text {obs: }}$ : observed LAI at flowering; $\mathrm{Y}_{\mathrm{DWN}}{ }^{*}$ : Yield simulated by Stics was "forced" so that LAIf ${ }_{\text {DWN }}=$ LAIf. $Y_{\text {obs }}$ : observed yield. $\left(\right.$ LAIf $_{\text {DWN }}-$ LAIf $\left._{\text {obb }}\right) / L_{\text {LAIf }}$ DWN and $\left(\mathrm{Y}_{\mathrm{DWN}}{ }^{*}-\mathrm{Y}_{\mathrm{obs}}\right) / \mathrm{Y}_{\mathrm{DWN}}{ }^{*}$ evaluate the growth reduction during the pre-flowering and post-flowering periods, respectively (see Tab. III).

requires detailed information on the biology of the weed species found in the plots and on the vertical distribution of leaves and roots in the weed-maize community, which was not recorded in our case. As an alternative, an empirical dynamic model was developed, considering the theoretical mechanisms described in the literature cited above, but with simplified assumptions permitted by the restricted regional scope of the model to be built. The resulting model and its coupling with Stics are presented in Appendices 1 and 2, respectively, the functions calculating weed growth being shown in Figure 6.

A set of four plots with contrasting weed dynamics was used to calibrate the weed module (Fig. 7). For the first half of the growing season, the dominant species were Digitaria horizontalis, Ageratum conyzoides, Sida rhombifolia or Ipomea acuminata. The botanical composition of the weed community varied between plots. After flowering, Pennisetum setosum was dominant in all of the plots in the set. In fact, this was also the case for most of the plots in the entire survey (data not shown). The calibration was performed assuming that the calibration coefficients were independent of the botanical composition of the simulated weed community. According to the modeling approach followed, this simplification was retained since it did not prevent the model from being satisfactorily calibrated (Fig. 7). 

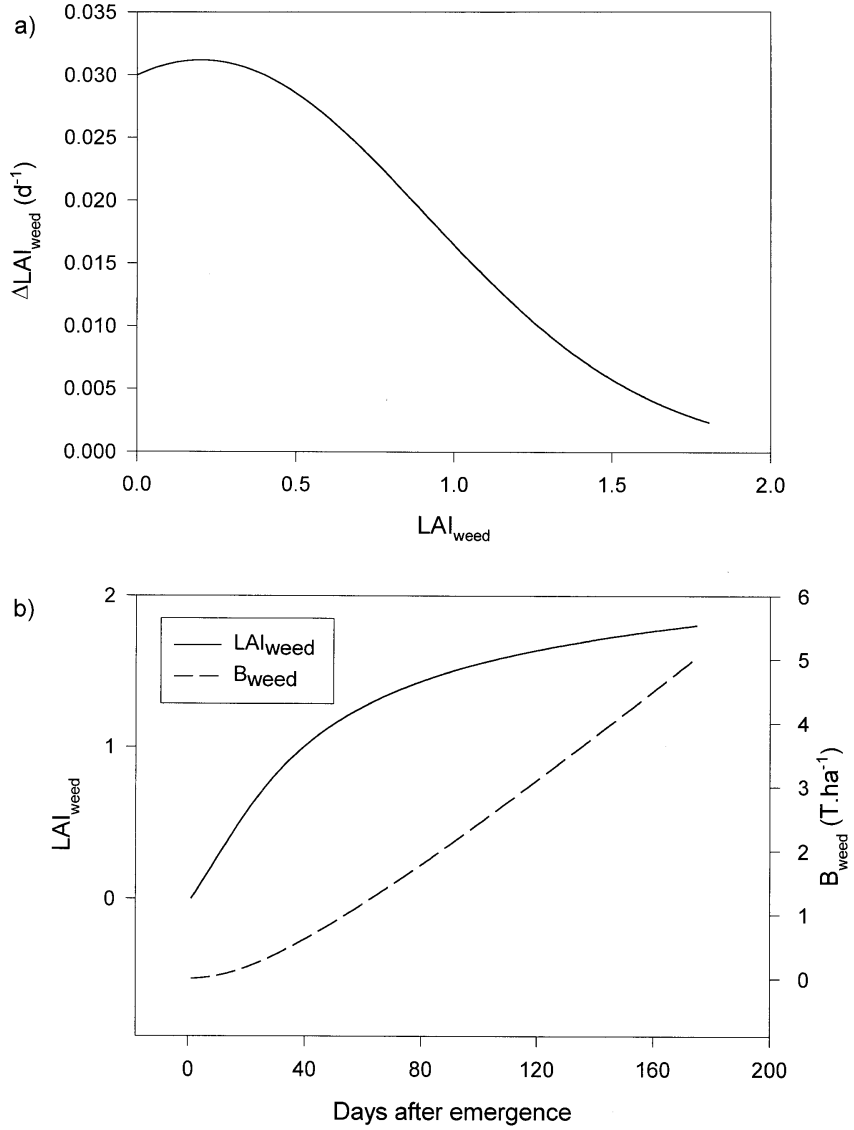

Figure 6. Functions simulating weed growth (see Appendix 1). (a) Daily increase in weed leaf area index $\left(\Delta \mathrm{LAI}_{\text {weed }}\right)$, and (b) growth of $\mathrm{LAI}_{\text {weed }}$ and weed biomass $\left(\mathrm{B}_{\text {weed }}\right)$. Stage II of the analysis.

\subsubsection{Other extra constraints ( $P, K$ and $O B)$ and the errors of Stics-modified}

A comparison between observed yields $\left(\mathrm{Y}_{\mathrm{obs}}\right)$ and yields simulated with Stics-modified ( $\mathrm{Y}_{\text {DWNAXH }}$ ) was performed, for the sub-sample of 54 plots (sub-sample D). These plots included the four that were used to calibrate the new functions. The fit between simulated and observed yields would not be improved by integrating the $\mathrm{P}, \mathrm{K}$ and $\mathrm{OB}$ extra constraints into Stics-modified since the graph in Figure 8 shows that the deviations between simulated and observed yields are not higher for the 18 plots in which these extra constraints could still be suspected according to their indicators, as opposed to the 36 plots where they were not present. This may be interpreted as a new application of Stage I, demonstrating that the effects (relative to $\mathrm{Y}_{\mathrm{DWNAXH}}$ ) of the $\mathrm{P}, \mathrm{K}$ and $\mathrm{OB}$ constraints could not be detected because they are of the same order of magnitude as the overall error of Stics-modified. This overall error of Stics-modified was approximately $20 \%$ of $\mathrm{Y}_{\text {DWNAXH }}$, as assessed by the deviation confidence interval between simulated and observed yields for the 36 plots with no extra constraints (mean relative deviation was 0.03 ; the $99 \%$ confidence interval of mean relative deviation was 0.17 ).
However, the fact that the error due to the remaining extraconstraints is not higher than the overall error of Sticsmodified does not mean that this overall error is the minimum that could be obtained in the conditions of the study. Checking this requires an estimation of the part of the error arising from measurement errors in the model's input variables (and propagated by the latter, "parameter error"), as well as the part resulting from the simplifying hypothesis used in the model ("structural error"). The parameter error was inherent in the measurements taken and thus could not be reduced, while the structural error might theoretically be decreased by improving the way processes are represented in Stics-modified. However, as recalled by Passioura [33], after Reynolds and Acock [35], this is likely to increase parameter error. Since overall error was known, the parameter error was estimated in order to obtain the structural error by subtraction, allowing us to check if their balance could be improved. This required an identification of the key input variables to which Sticsmodified was the most sensitive, as well as those associated with important measurement errors. The sensitivity analysis of the next stage (Stage III) had to be performed first in order to identify these key variables, and this analysis of Sticsmodified errors was actually carried out a posteriori, but its results are presented here, due to their more direct link with the present subsection.

Among the input variables detected in the next stage (Stage III) as strongly influencing simulated yields, three were associated with measurement errors slightly over or under $20 \%$ (data not shown):

- available soil water capacity (AWC, error partly assessed by comparing the protocol used in the survey with a reference protocol; see Sect. 2.5);

- distribution of organic $\mathrm{N}$ in the soil profile (error assessed by comparing the two methods of soil sampling);

- $\mathrm{N}$ fertilization applied by farmers, this latter error being due to errors on the surface area of the fields (what was known was the total amount of $\mathrm{N}$ applied to the entire field; the error was detected and evaluated a posteriori when the area of some fields was checked using a theodolite, showing that it differed from the data provided by the farmers).

Aiming to evaluate the impact of these errors on the simulations, a simplified Monte-Carlo analysis was carried out as follows. New simulations were performed with Sticsmodified, for the 36 plots (extracted from sample D in Fig. 8) in which no extra constraints (relative to Stics-modified) could be suspected. In these simulations, for each plot, the preceding three input variables were varied between three levels: the value measured in the plot, and this value plus and minus $20 \%$. All the other input variables were given the value observed in the plot. The confidence interval of the resulting 27 simulations of each plot was compared with the deviations between the standard simulation (all inputs at observed values) and the observed yield (Fig. 9). For most plots, the "noise" due to parameter error exceeded the deviation between the standard simulation and observation. This indicated that the parameter error dominates in the overall error of the model. Thus, with the experimental data of this study, the precision of Stics-modified could not be improved by further modeling aiming at a lower structural error. 


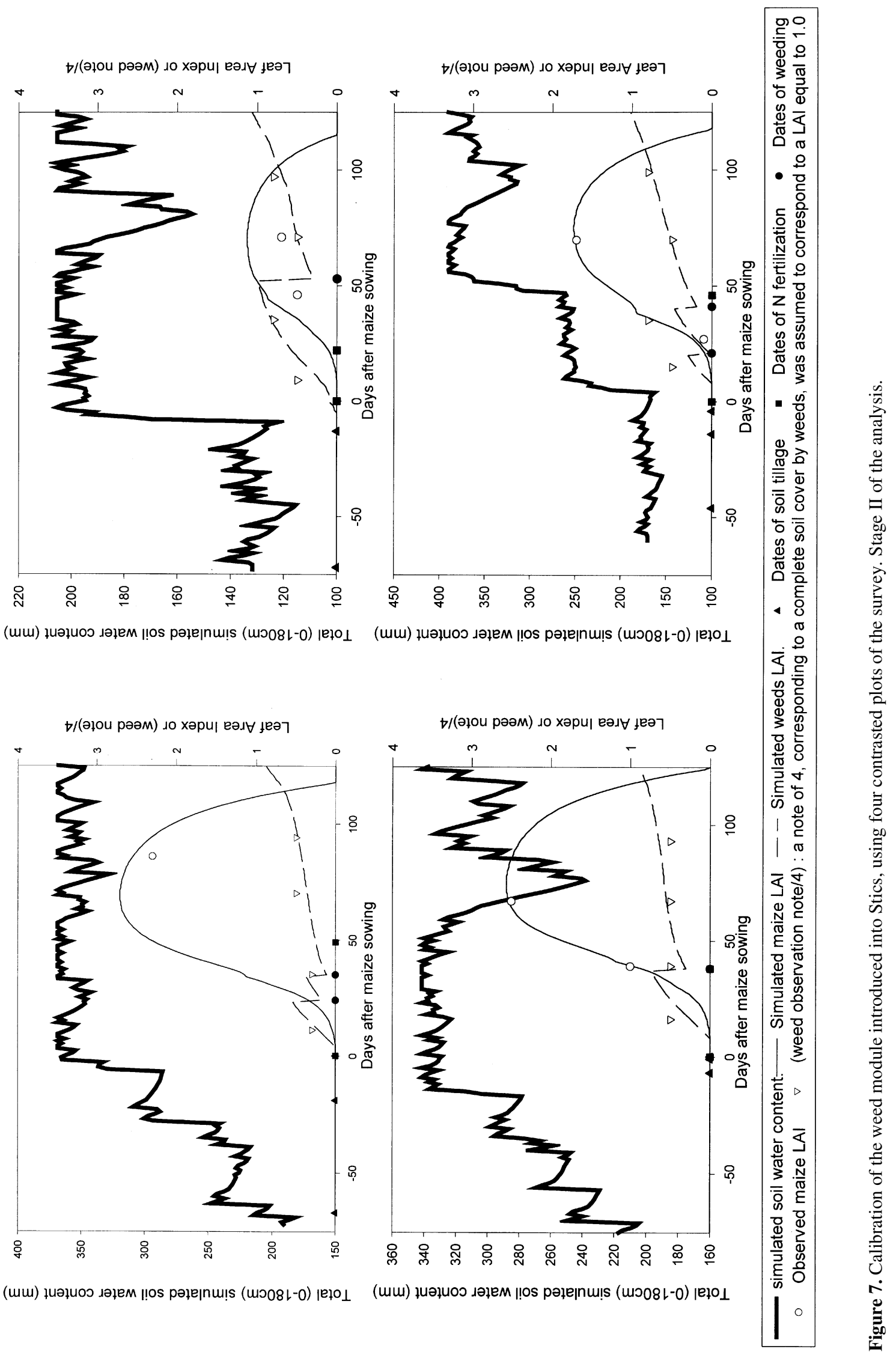




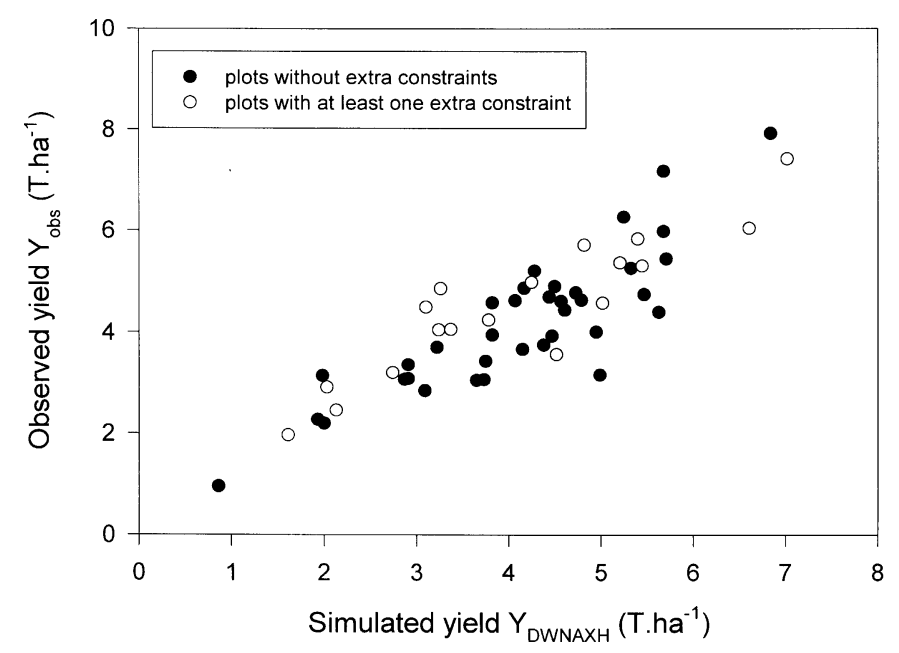

Figure 8. Relation between observed $\left(\mathrm{Y}_{\text {obs }}\right)$ and simulated yields ( $\mathrm{Y}_{\text {DWNAXH }}$ ) using Stics-modified. Stics-modified accounts for the constraints weeds $(\mathrm{H}), \mathrm{Al} / \mathrm{Ca}(\mathrm{A})$ and water excess $(\mathrm{X})$ constraints (newly added) and for low stand density (D), water (W) and nitrogen (N) constraints (already accounted for by Stics). Extra constraints, relative to the new model are $\mathrm{P}, \mathrm{K}$ and $\mathrm{OB}$ (phosphorus, potassium and other biotic constraints, respectively).

Consequently, the effects on yields of the $\mathrm{P}, \mathrm{K}$ and OB constraints were ignored in the remaining part of the study, and Stics-modified was assumed to be valid for its uses in the next Stage (Stage III) in this regional context, taking into account its $20 \%$ overall error. As already stated, an independent validation would be required for an application in another context.

\subsection{Final diagnosis (Stage III)}

The Stage III analysis was performed using the subsample $\mathrm{C}$ of 86 plots, except for the analysis involving the $\mathrm{Y}_{\mathrm{A}}$ and $\mathrm{Y}_{\mathrm{H}}$ simulations, which required input data that was only available for the sub-sample D of 54 plots. In this section, first the main effects of the modeled constraints are studied, using simulations of $\mathrm{Y}_{0}, \mathrm{Y}_{\mathrm{D}}, \mathrm{Y}_{\mathrm{W}}, \mathrm{Y}_{\mathrm{N}}, \mathrm{Y}_{\mathrm{A}}, \mathrm{Y}_{\mathrm{H}}$ and $\mathrm{Y}_{\mathrm{X}}$ for each plot of the sample, the mean and frequency of values in the sample being considered. Then, a similar analysis of the interactions between constraints is presented, involving simulations of $\mathrm{Y}_{\mathrm{c}_{1} \ldots \mathrm{c}_{\mathrm{k}}}$ where $\mathrm{c}_{1} \ldots \mathrm{c}_{\mathrm{k}}$ is any of the $2^{6}$ possible combinations in which each of the subscripts D, W, N, A, H and X is present or lacking. For the modeled constraints which markedly affected simulated yields according to this analysis, a third sub-section reports the analysis of their effects in relation to the main input data of Stics-modified. This allowed the detection of the characteristics of the cropped system that were dominating as causes of yield losses.

\subsubsection{Simulated main effects of constraints}

The sowing date and the time-variability of radiation and temperature were shown to have little impact on simulated yield potential in Silvânia: $\mathrm{Y}_{0}$ ranged from 7.69-10.78 Mg/ha, with a variation coefficient of $8.0 \%$, whereas observed yields

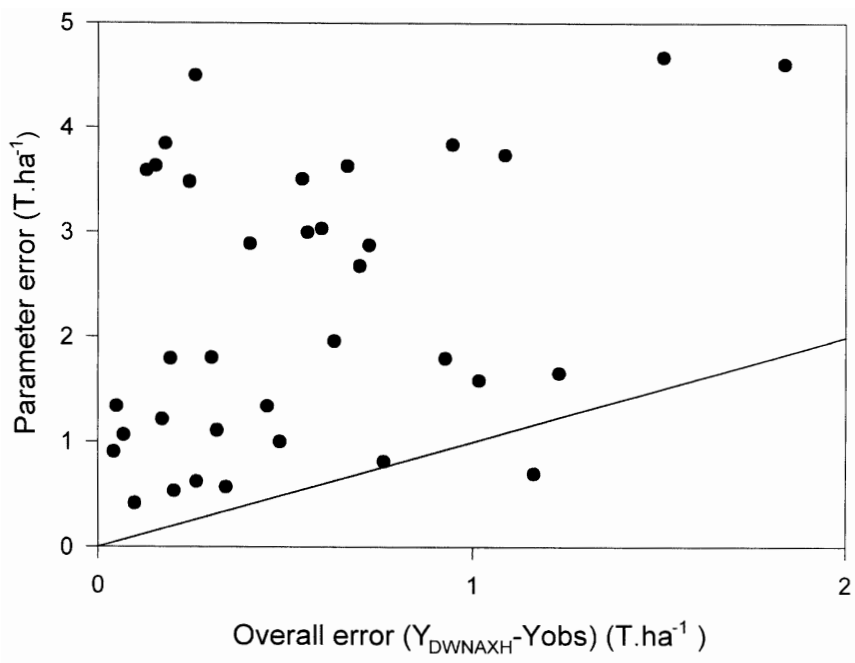

Figure 9. Relation between overall error and parameter error of Stics-modified (line=1:1 line). Stage II of the analysis. Set of 36 plots without extra constraints (relatively to Stics-modified) extracted from sub-sample D. Parameter error was assessed through a simplified Monte-Carlo analysis on key input variables (AWC, $\mathrm{N}$-fertilization, organic $\mathrm{N}$ in soil), whereas all other input variables were at the levels observed in the plots.

ranged from $0.58-8.03 \mathrm{Mg} / \mathrm{ha}$ with a much higher variation coefficient of $37 \%$.

The mean main effects of constraints are given in Figure 10, considering both their mean influence on yields and the frequency in which they caused yield reduction over $10 \%$. Plant density varied considerably in the plot sample, ranging from 1.8-7.7 plants per $\mathrm{m}^{2}$. However, the simulated individual effect of the D constraint on yield was only slight. The water constraint (W) had a more marked simulated effect than the latter in terms of both frequency of occurrence and impact on yield. The simulated nitrogen constraint (N) had even more impact than $\mathrm{W}$, mainly in terms of the frequency of occurrence (Fig. 10).

The Al/Ca (A) and water excess (X) constraints have no simulated main effect because in the model they only modify root depth (as defined, the simulated yields $\mathrm{Y}_{\mathrm{A}}$ and $\mathrm{Y}_{\mathrm{X}}$ are obtained with non-limiting input variables for water and nitrogen balances, and are always equal to $\mathrm{Y}_{0}$ ). The simulated yield reductions due to the $\mathrm{A}$ or $\mathrm{X}$ constraints are only due to the interactions between limited root depth and the water and nitrogen dynamics. These interactions are analyzed in Section 3.3.2.

The simulated main effect of the weed constraint $(\mathrm{H})$ was moderate $(22 \%)$, but it affected half of the plot sample. It only concerns competition between maize and weeds for solar radiation. Competition for water and nitrogen is analyzed in Section 3.3.2 as an interaction between constraints.

\subsubsection{Simulated interactions between constraints}

According to Section 2.7, yield reductions are calculated relative to $\mathrm{Y}_{0}$, so that the interactions are also expressed in relative yield losses. As a result, the interactions referred to hereafter are positive when they aggravate the yield reduction, 


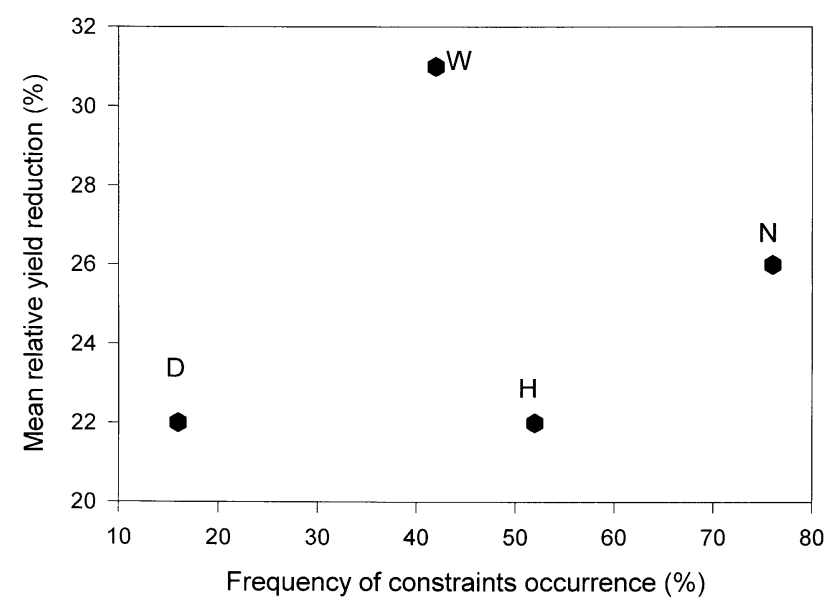

Figure 10. Single effects of the main constraints, as simulated using Stics-modified. Stage III of the analysis. See Table I for definition of symbols D, N, H and W. Frequency of occurrence: proportion of plots in which simulated yield reduction in relation to simulated yield potential $\mathrm{Y}_{0}$ (relative yield reduction) was over $10 \%$, taking into account the observed level for the considered constraint and unlimiting levels for the other constraints. Relative yield reduction was averaged (Y-coordinate), discarding plots with yield reduction below $10 \%$. As simulated, A and $\mathrm{X}$ constraints have no single effect.

and negative otherwise. In cases of occurrences of both plots with negative values and plots with positive values for a given interaction, the means of the negative cases and of the positive cases were calculated separately. In the following, the term "absolute value" is used in reference to the sign and should not be understood as opposed to "relative value" of yield reduction.

The main simulated interactions between constraints are shown in Figure 11. All the interactions were calculated, but only those surpassing $10 \%$ in absolute value are displayed in the graph.

Water excess had little effect on simulated yields: its single effect $X$ was null, as seen above, and its interaction with the other constraints was always lower than $10 \%$ in absolute value. It is therefore not displayed in the graph.

Given the expected decrease in crop requirements for water and nitrogen caused by low plant densities, the simulated effect of the D constraint (a high value of D corresponding to insufficient densities) on yields reduced the $\mathrm{N}$ and $\mathrm{W}$ constraints, hence a negative value for the interactions involving the three constraints as shown by the DNW-value in Figure 11; the reduction of yield is less than expected from the cumulating main effects of $\mathrm{D}, \mathrm{N}$ and $\mathrm{W}$. There was a strong (absolute value) and positive interaction between the $\mathrm{N}$ and W constraints (NW + value). In $19 \%$ of cases their combined effect was higher than the sum of their individual effects, which is probably due to the fact that $\mathrm{N}$ absorption decreases when soil water content decreases. However, in $23 \%$ of the plots, the interaction was negative but with a lower absolute value (NW-). In most of these plots, the detailed simulation reports (data not shown) showed that the $\mathrm{W}$ stress took place early in the crop cycle, decreasing the crop $\mathrm{N}$ requirement for the rest of the cycle. In fact, in these plots a strong $\mathrm{N}$ stress

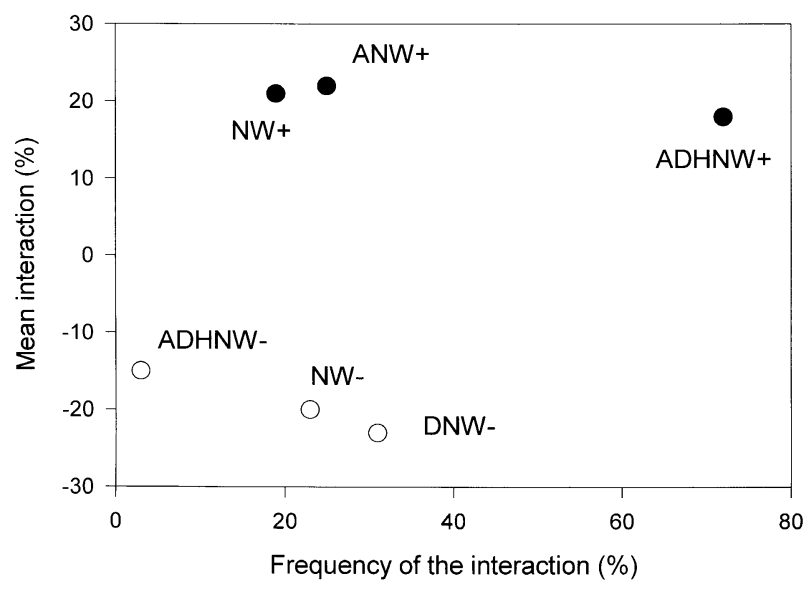

Figure 11. Simulated interactions between the modeled constraints using Stics-modified. Stage III of the analysis. See Table I for definition of symbols A, D, H, N and W. Interaction is the difference between the overall effect of a set of constraints and the sum of the main effects of each constraint in the set. Interactions were averaged separately for negative (- symbol; lower yield reduction than expected from the sum of the main effects) and positive cases (+ symbol, higher yield reduction than expected from the sum of the main effects). Frequency of a given interaction is the proportion of plots in which this interaction exceeded $10 \%$ in absolute value. Interactions below $10 \%$ in absolute value are not displayed (e.g. as in the case of the water excess constraint (X) whose simulated interaction with any set of other constraints was below 10\%).

would have been recorded if no water stress had first occurred, due to the lack of the second $\mathrm{N}$ application usually done at the end of the juvenile growth stage. This period coincided with a lack of rainfall in these plots. Thus, the low $\mathrm{N}$ fertilization levels may reflect a rational tactical response by farmers facing adverse climatic conditions, in order to reduce fertilizer costs.

In a quarter of the sample, the $\mathrm{Al} / \mathrm{Ca}$ constraint $(\mathrm{A})$ resulted in a strong positive interaction with the $\mathrm{D}, \mathrm{N}$ and $\mathrm{W}$ constraints $(\mathrm{ANW}+)$, meaning that $\mathrm{A}$ was aggravating yield reductions due to these constraints.

The interaction between weeds $(\mathrm{H})$ and the $\mathrm{D}, \mathrm{W}, \mathrm{N}$ and A constraints was generally positive (ADHNW+), most likely because low maize growth encouraged weed growth. However, this interaction was negative (ADHNW-) in 3\% of the plots. These were plots where the $\mathrm{W}, \mathrm{N}$ or A constraints were particularly strong (data not shown). It would seem that the direct negative effect of the $\mathrm{W}, \mathrm{N}$ or $\mathrm{A}$ constraints on weeds outweighed the preceding ones, and the indirect effect of low maize growth favoring weed growth.

Although low plant density (D constraint) had relatively little direct impact on potential yield $\mathrm{Y}_{0}$, as seen above, its simulated interactions with the other constraints could not be ignored (D appeared in several interactions in Fig. 11). Particularly, it is likely that it encouraged weed infestation (ADHNW+). However, the DH interaction was lower than $10 \%$ (and thus not displayed on the graph), which suggests that $\mathrm{D}$ alone was not as favorable to weeds as was its conjunction with the other constraints $\mathrm{A}, \mathrm{N}$ and $\mathrm{W}$. 
Table V. Role played by rainfall (RA), available water capacity (AWC) and runoff (RF) in water constraint occurrence, as simulated with Stics-modified ${ }^{1}$. Stage III of the analysis.

\begin{tabular}{|c|c|c|c|}
\hline \multirow[b]{2}{*}{$\begin{array}{l}\text { Simulated yield reduction relative } \\
\text { to yield potential }(\%)\end{array}$} & \multicolumn{3}{|c|}{ Frequency (\% plots) of yield reduction according to hypotheses on the main variables affecting water balance } \\
\hline & $\begin{array}{c}\text { effect of rainfall alone: } \\
\text { - Observed RA } \\
\text { - AWC }=180 \mathrm{~mm} \\
(100 \mathrm{~mm} / \mathrm{m} \text { of soil }) \\
\text { - RF }=0 \mathrm{~mm}\end{array}$ & $\begin{array}{c}\text { Addition of the AWC effect: } \\
\text { - Observed RA } \\
\text { - Observed AWC } \\
\text { - RF }=0 \mathrm{~mm}\end{array}$ & $\begin{array}{c}\text { Addition of runoff effect: } \\
\text { - Observed RA } \\
\text { - Observed AWC } \\
\text { - RF }=0.3 \times \text { RA if RA >15 mm }\end{array}$ \\
\hline$\leq 10$ & 83 & 58 & 58 \\
\hline$>10$ and $\leq 30$ & 7 & 22 & 22 \\
\hline$>30$ and $\leq 50$ & 10 & 15 & 15 \\
\hline$>50$ and $\leq 70$ & 0 & 5 & 5 \\
\hline$>70$ & 0 & 0 & 0 \\
\hline
\end{tabular}

The input variables still not introduced into the simulations corresponding to a column were given reference values, whereas all the other input variables were given observed values. However, in the case of RF, which was not measured, a strong runoff ( $30 \%$ of any rainfall over $15 \mathrm{~mm}$ ) was tested, instead of observed values. Sub-sample C ( 86 plots).

${ }^{1}$ The new functions are not utilized in these simulations. Identical results would have been obtained using Stics.

\subsubsection{Input variables dominating as causes of simulated constraint effects}

The two preceding sub-sections showed that the $\mathrm{W}, \mathrm{N}$ and $\mathrm{H}$ constraints played an important role in simulated yield reductions, through their main effects as well as through their interactions. D and A contributed to the overall yield gap through their interactions with the other constraints. The water excess constraint $(\mathrm{X})$ was the only modeled constraint whose effects on yield could be ignored. Thus, this sub-section aims to detect which input variables dominate as causes of the effects of each of the modeled constraints, except X. However, in Stics-modified, D and A levels are each determined by a single input variable: plant density determining $\mathrm{D}$ and the soil depth at which $\mathrm{Al}$ toxicity/Ca deficiency occurs determining A. Therefore, such an analysis is useless for these constraints. As a consequence, the $\mathrm{W}, \mathrm{N}$ and $\mathrm{H}$ constraints will be focused on below.

Considering the input variables that affect the $\mathrm{W}$ constraint (Tab. V), we find that the amount of rainfall was not a limiting factor for the simulated yield of maize crops in Silvânia during the years under study, even when considering that $30 \%$ of the rainfall was lost through runoff, and despite the fact that one of the seasons under study (1995-1996) was one of the 3 driest years in a 15-year climatic series [38]. On the contrary, available soil water capacity (AWC) appeared to be an important causal factor affecting the simulated yield. Although the sowing date was highly variable in the plot sample, it is not assessed in the preceding analysis in the same way as effects due to AWC and runoff are, because this would have involved a large number of simulations. The analysis used above demonstrated that runoff and rainfall had little effect compared with AWC. As a result, it was possible to focus on the interaction between sowing dates and AWC, by analyzing the response surface of simulated yields $\mathrm{Y}_{\mathrm{W}}$, compared with the observed AWC and sowing dates (Fig. 12). When AWC is greater than $120 \mathrm{~mm}$, it is graphically visible that $\mathrm{Y}_{\mathrm{W}}$ is notably constant and high for a wide range of sowing dates. On the contrary, simulated water stress clearly depends on the sowing dates for fields where AWC ranges from $75-120 \mathrm{~mm}$. For soils with such low water storage capacity, it would be useful to determine optimal sowing dates by performing frequency analyses of $\mathrm{Y}_{\mathrm{w}} / \mathrm{Y}_{0}$ over a long-term climatic series.

As reported in Table VI, most of the simulated effects of the $\mathrm{N}$ constraint are linked to the variability of $\mathrm{N}$-fertilizer applications, to AWC, and, to a lesser extent, to the soil organic $\mathrm{N}$ content. This suggests that: (i) the simulated mineralization rate was slightly variable; (ii) the $\mathrm{N}$-fertilizer applications were often insufficient, and (iii) simulated $\mathrm{N}$ losses through leaching were high, as indicated in the last case by the sensitivity of simulated yield $\mathrm{Y}_{\mathrm{N}}$ to AWC. This was confirmed by an examination of the detailed simulation reports which included the simulated amounts of $\mathrm{N}$ leached and mineralized (data not shown). These indicate that optimization of sowing dates should aim at risk reduction not only for water stresses, but also for such $\mathrm{N}$ losses. In the short term, $\mathrm{N}$-fertility management could be improved by adjusting the fertilizer applications to the soil's organic $\mathrm{N}$ content. However, in the long term, it is likely that the soil's organic matter will decrease due to the lack of an organic manure application in most fields. Alternative methods of managing organic matter at farm level should be investigated.

Weed (H constraint) effect was mainly due to: (i) the poor timing of weeding, and (ii) with less impact on yield, to weeding failure due to climatic conditions. When delays between the last soil tillage and the sowing date were taken into account, the number of plots affected by $\mathrm{H}$ slightly increased and the simulated yield losses were higher (Tab. VII).

As a synthesis of the diagnosis progressively performed and presented in this results section, it may be stated that the yield gap in the region under study was not due to a few predominant causes but rather to the combination of numerous constraints and the complex interactions between them. The main environmental limitations were low soil water capacities, often aggravated by Aluminum toxicity or Ca deficiency reducing root growth. The main technical weaknesses of the local cropping systems were inappropriate sowing dates, $\mathrm{N}$-fertilization and weeding sequences, as well as delays between tillage and sowing favoring highly constraining weed populations. These were 


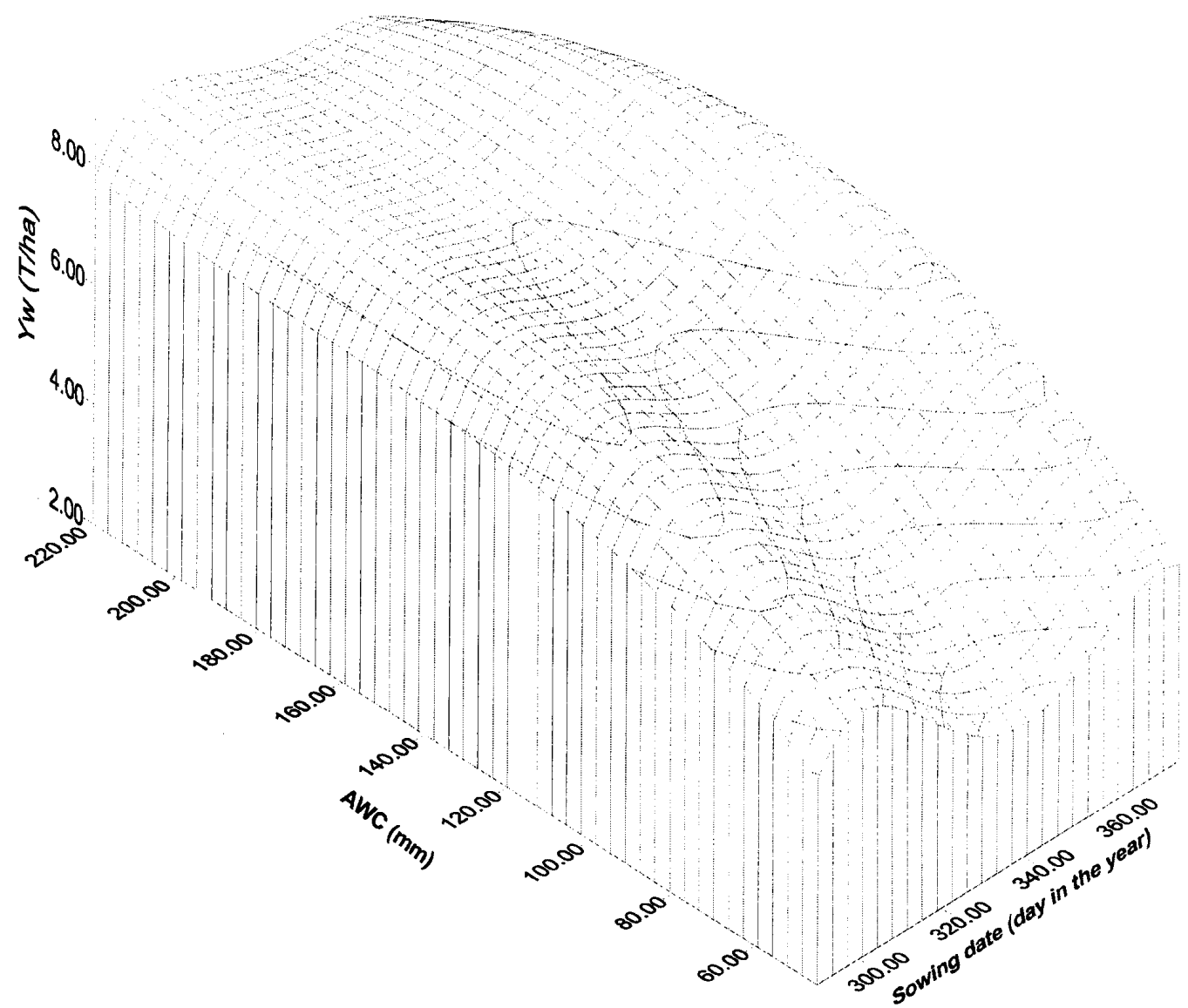

Figure 12. Surface response of simulated $Y_{w}$ to sowing date and available water capacity (AWC). $Y_{w}$ is the yield simulated under the hypothesis that only the water constraint is limiting.

Table VI. Role played by the main variables affecting nitrogen balance with the occurrence of the nitrogen constraint as simulated by Sticsmodified $^{1}$. Stage III of the analysis.

\begin{tabular}{|c|c|c|c|c|}
\hline \multirow[b]{2}{*}{$\begin{array}{l}\text { Simulated yield } \\
\text { reduction relative } \\
\text { to yield potential } \\
\text { (\%) }\end{array}$} & \multicolumn{4}{|c|}{ Frequency (\% plots) of yield reduction according to hypotheses on the main variables affecting nitrogen balance } \\
\hline & $\begin{array}{c}\text { Effect of N from fertilizers } \\
\text { - observed fertilization } \\
\text { - "Reference soil" }(\mathrm{AWC}=180 \mathrm{~mm} \text {, } \\
\text { organic } \mathrm{N} \text { in soil }=5 \mathrm{~T} / \mathrm{ha} \text {, clay } \\
\text { content }=35 \%) \\
\text { - no organic manure }\end{array}$ & $\begin{array}{c}\text { Addition of the effect } \\
\text { of organic } \mathrm{N} \text { in soil: } \\
\text { as in left column, but } \\
\text { with observed organic } \mathrm{N} \\
\text { in soil }\end{array}$ & $\begin{array}{c}\text { Addition of the effect } \\
\text { of observed AWC (resulting } \\
\text { in varying N lixiviation): } \\
\text { as in the preceding column, } \\
\text { with observed soil }\end{array}$ & $\begin{array}{l}\text { Addition of the effects } \\
\text { of organic manure: } \\
\text { all input variables for } \\
\mathrm{N} \text { balance as observed }\end{array}$ \\
\hline$\leq 10$ & 54 & 44 & 22 & 25 \\
\hline$\leq 30$ and $>10$ & 44 & 44 & 54 & 49 \\
\hline$\leq 50$ and $>30$ & 2 & 16 & 22 & 25 \\
\hline$\leq 70$ and $>50$ & 0 & 0 & 2 & 1 \\
\hline$>70$ & 0 & 0 & 0 & 0 \\
\hline
\end{tabular}

Same principle as in Table V: the input variables still not introduced into the simulations corresponding to a column were given reference values, whereas all the other input variables were given observed values. Sub-sample C ( 86 plots).

${ }^{1}$ The new functions are not utilized in these simulations. Identical results would have been obtained using Stics. 
Table VII. Role played by the main variables affecting weed growth with the occurrence of the weed constraint, as simulated by Sticsmodified. Stage III of the analysis.

\begin{tabular}{|c|c|c|c|}
\hline \multirow[b]{2}{*}{$\begin{array}{l}\text { Simulated yield reduction } \\
\text { relative to yield potential }(\%)\end{array}$} & \multicolumn{3}{|c|}{ Frequency (\% plots) of yield reduction according to hypotheses on the main variables affecting weed growth } \\
\hline & $\begin{array}{c}\text { Effect of weeding sequence, without } \\
\text { interaction with rainfall } \\
\text { - last tillage }=\text { sowing date } \\
\text { - observed weeding sequence } \\
\text { - weeding efficiency }=1\end{array}$ & $\begin{array}{l}\text { Addition of the effect of } \\
\text { rainfall on weeding efficiency: } \\
\text { as in left column, but with } \\
\text { simulated weeding efficiency }\end{array}$ & $\begin{array}{l}\text { Addition of the effect of observed } \\
\text { time interval between last tillage } \\
\text { and sowing date: } \\
\text { all input variables for weed module } \\
\text { as observed }\end{array}$ \\
\hline$\leq 10$ & 74 & 55 & 48 \\
\hline$\leq 30$ and $>10$ & 26 & 45 & 44 \\
\hline$\leq 50$ and $>30$ & 0 & 0 & 7 \\
\hline$\leq 70$ and $>50$ & 0 & 0 & 1 \\
\hline$>70$ & 0 & 0 & 0 \\
\hline
\end{tabular}

Same principle as in Table V: the input variables still not introduced into the simulations corresponding to a column were given reference values, whereas all the other input variables were given observed values. Sub-sample D (54 plots).

also favored by low plant densities at emergence. As compared with the information available at the start of the study (Tab. I) for the region, this diagnosis enlightened the complex interactions leading to weed infestation, showed that the water constraint was less due to a climatic constraint than to soil characteristics and sowing dates, and indicated the relatively low importance of water excess, $\mathrm{P}$ and $\mathrm{K}$ constraints and insects and diseases. However, further diagnosis is required in order to identify the technical and environmental causes of these low plant densities. Due to the fact that the model was not considering the elaboration of this variable, this involved the qualitative method of [18], and has not been reported here.

\section{DISCUSSION}

The proposed methodology was adopted in an attempt to evaluate the impact of constraints on yields in a given region, from a possibly novel and more objective perspective. From a relatively large set of constraints that could a priori be suspected of involvement in local yield gaps, the method progressively allowed the identification of those constraints occurring most frequently, and moreover, those responsible for the strongest impact on yields. Its final results were:

- a list of environmental and technical characteristics that were the main causes of these constraints at croppingsystem level and hence of local yield gaps;

- a simulation model tailored to the local context, able to simulate yield elaboration of most crop situations (Sticsmodified).

This ad hoc model could be used in the future to investigate the effects of the constraints, as well as the effects of corrective actions for long-term climatic series [32]. This would allow for further-reaching conclusions that would be applicable to situations that are more representative of the local cropping conditions than of the 3 years that were monitored. [40] expressed the need for such ad hoc models, as opposed to the utopian "universal model", and provided guidelines for this purpose. One important aspect highlighted by these authors is that the model should take into account the local hierarchy of the variables involved in the process to be simulated. They did not mention, however, any method for establishing such a hierarchy. In our work, the diagnosis fed, as well as was fed by, the building of the model. We do not pretend that this was fully objective, but the diagnosis provided a pragmatic basis for selecting the variables to be accounted for by the model and for ignoring others. In that sense, the method we followed should be further explored as a methodological contribution to ad hoc modeling.

Due to the above, we believe that our methodology could bring progress to the difficult task of diagnosis, but we are also aware of its possible limitations.

First, it could be argued that the list of constraints established at Stage 0 as a starting point for the diagnosis may not be exhaustive. This drawback is already present in the methodology from [18], in which Stage 0 implicitly exists. However, if any of the major constraints were omitted, it may be considered unlikely that a good fit between simulations and observations would have been obtained with the modified model.

Second, it is not obvious, at the end of Stage I, which extra constraints have to be incorporated into the model and which may be ignored. Our choice of modeling for the three most frequent extra constraints may appear somewhat arbitrary. This choice was partly and a posteriori justified by the fact that the remaining extra gap was lower than the overall error of the modified model. However, this choice led to the modeling of the $\mathrm{X}$ constraint, which ended up having little influence on yields. Should the model be further applied, the functions simulating X constraint effects may be removed.

Third, the modeling process was limited by the data available from the survey. The number of situations for which all the required data was available for the simulations decreased as the model became more complex. As a result, the calibration and validation of Stics-modified remained imperfect. The main cause of these limitations is that it was difficult to predict, at the outset of the study, which constraints, among the relatively numerous ones suspected at stage 0 , the modeling would have to focus on. Consequently, the measurement effort (which was considerable given the on-farm context and the 
area covered) was shared out among the numerous variables, instead of concentrating on those that were eventually demonstrated to be the most relevant. This drawback could possibly be avoided in future similar studies by adapting the measurement device from one year to the next, as far as the analysis of the available information permits the narrowing of the field of investigation. Another problem that could limit the modeling process, should the method be used in other situations, is the possible lack of existing theoretical knowledge needed to model some of the local constraints. In such a case, additional work would be needed to obtain the lacking information. This is similar to what occurred in several diagnosis works in which additional experiments were necessary to study the effects of some constraints in environments where they were imperfectly known $[6,16,37]$.

Fourth, and finally, several subjective aspects were involved in the assessment, by simulation, of the impact of the constraints and of their related environmental and technical variables (Stage III). The main one is that the error of the model was imperfectly known. Particularly, as already stated in the sub-section dealing with the methodology of this Stage, only the error of the overall model was approximated, and not the errors associated with the simulations of each constraint separately (errors associated with $\mathrm{Y}_{\mathrm{D}}, \mathrm{Y}_{\mathrm{W}}, \mathrm{Y}_{\mathrm{N}}, \ldots$ ) nor those associated with the simulations of interactions between constraints $\left(\mathrm{Y}_{\mathrm{DW}}, \mathrm{Y}_{\mathrm{DN}}, \mathrm{Y}_{\mathrm{DWN}}, \mathrm{Y}_{\mathrm{DNWA}}, \ldots\right)$. This drawback is inherent in the on-farm diagnosis, as far as an ANOVA device cannot practically take place in such a context, since this would be the only rigorous way to estimate these errors. Another subjective aspect arose from the fact that not all the interactions between the input variables of Stics-modified were tested, when detecting those responsible for the strongest simulated yield reductions. The procedure used required "expert's choices" that may appear somehow arbitrary, such as the order in which the variables are added to the simulations. This was due to the size of the problem to be tackled (the dimension of the analyzed space). It would be theoretically possible to conceive an automatic procedure avoiding this, but computing time might become limiting, and this drawback may probably be minor, as compared with the preceding one which we assumed that could not be avoided.

\section{CONCLUSION}

The study showed that the building and use of an ad hoc crop model allowed a more objective way to diagnose the main weaknesses of cropping systems in the complex situations encountered in real farming conditions across a region. Some aspects of this diagnostic method, however, require a qualitative analysis and involve "expert's choices". In order to improve the method, these more speculative aspects deserve further research efforts, although some are probably inherent in the on-farm diagnosis task.

It is not intended that the scope of the new functions incorporated into the Stics model exceed the studied region. However, the validity domain of the approach followed in the modeling of weed/crop interactions should be further explored, since it may be a convenient compromise between the rather crude use of a reduction coefficient applied to final yields, and more complex models based on 2-D representations of the canopy of the crop-weed community.

Last, the proposed diagnostic method could also be further explored as a contribution to ad hoc modeling.

Acknowledgments: This research was conducted at EMBRAPACerrados. We would like to express our gratitude to all those at the center, and those from CIRAD, who contributed to the research. We would especially like to thank F. Macena, L.F. Zoby, F. Maraux, F. Forest, and N. Brisson for their contribution through discussions, criticism and support, and B. Evangelista, V. De Oliveira Pais and J.C. Gonçalves dos Santos for their invaluable help in the field, as well as all the farmers of Silvânia who generously gave their time to partake in the survey. We are also grateful to Prof. J.F. Ledent for his numerous suggestions that greatly contributed to the final version of this paper.

\section{APPENDIX 1: MODEL OF WEED GROWTH}

Potential daily growth for weed biomass $\left(\Delta \mathrm{B}_{\text {weed }}(\mathrm{d})\right.$, $\left.\mathrm{kg} \cdot \mathrm{ha}^{-1} \cdot \mathrm{d}^{-1}\right)$ and leaf area index $\left(\Delta \mathrm{LAI}_{\text {weed, }} \mathrm{m}^{2} \cdot \mathrm{m}^{-2} \cdot \mathrm{d}^{-1}\right)$ was introduced. $\Delta \mathrm{LAI}_{\text {weed }}$ is a decreasing function of daily value for weed leaf area index $\mathrm{LAI}_{\text {weed }}$ (Fig. 6a), producing an asymptotic time-evolution for $\mathrm{LAI}_{\text {weed }}$ when no stress occurs (Fig. 6b). $\Delta \mathrm{B}_{\text {weed }}(\mathrm{d})$ is obtained using a simplified equation that accounts for light interception by weeds:

$$
\Delta \mathrm{B}_{\text {weed }}(\mathrm{d})=\operatorname{Ew}\left[1-\mathrm{e}^{(-\mathrm{kw} \text { LAIweed }(\mathrm{d}))}\right],
$$

where $\mathrm{k}_{\mathrm{w}}$ (dimensionless) is the extinction coefficient for weeds, considered as a calibration constant for a given weed community, and Ew $\left(\mathrm{kg} \cdot \mathrm{ha}^{-1} \cdot \mathrm{d}^{-1}\right)$ is the product of incoming radiation at the top of the canopy and radiation use efficiency. Given the low variability of daily global radiation in the region under study, as opposed to variability of water and nitrogen constraints, Ew was approximated as a calibration constant.

$\mathrm{S}_{\text {weed }}$, a "stress" coefficient ranging from 0-1 (dimensionless), accounts for water and nitrogen constraints (SW and $\mathrm{SN}_{\text {weed }}$, respectively), and for light interception by maize crops competing with weeds (exponential factor):

$$
\mathrm{S}_{\text {weed }}=\mathrm{e}^{(-\mathrm{k} * \mathrm{LAI})} \times \operatorname{Min}\left(\mathrm{SW}, \mathrm{SN}_{\text {weed }}\right),
$$

where Min(list) is the minimum value on the list, $\mathrm{k}$ the extinction coefficient for maize, and LAI the daily simulated value of leaf area index for maize.

$\mathrm{S}_{\text {weed }}$ reduces the daily potential growths:

$$
\begin{gathered}
\operatorname{LAI}_{\text {weed }}(\mathrm{d})=\mathrm{LAI}_{\text {weed }}(\mathrm{d}-1)+\Delta \mathrm{LAI}_{\text {weed }}(\mathrm{d}) \times \mathrm{S}_{\text {weed }} \\
\mathrm{B}_{\text {weed }}(\mathrm{d})=\mathrm{B}_{\text {weed }}(\mathrm{d}-1)+\Delta \mathrm{B}_{\text {weed }}(\mathrm{d}) \times \mathrm{S}_{\text {weed }}
\end{gathered}
$$

Weed emergence is calculated using the function describing maize emergence in Stics, assuming that weed germination starts the day after the last soil tillage operation. This means that any preceding tillage is assumed to have suppressed all weeds that had previously grown since the beginning of the rainy season, and that the effects of this early weed population on the water and nitrogen balances of the crop are ignored. This simplification seemed reasonable in our context, given the low levels of weed infestation at the beginning of the cropping season in our plots (data not shown). Mechanical weeding and contact herbicides are both considered to nullify 
$\mathrm{LAI}_{\text {weed }}$ and $\mathrm{B}_{\text {weed }}$ on the day they are applied. When it rains on the same day as the operation, or on the day after, however, $\mathrm{LAI}_{\text {weed }}$ and $\mathrm{B}_{\text {weed }}$ are reduced by only half. Pre-emergence herbicides are considered to maintain $\mathrm{LAI}_{\text {weed }}$ and $\mathrm{B}_{\text {weed }}$ at 0 value for 50 days.

\section{APPENDIX 2: WEED COMPETITION INTRODUCED INTO STICS}

The effects of weeds on maize growth were incorporated into Stics as follows. According to the approach used by Wiles and Wilkerson [44], when LAI+LAI weed $_{\text {exceeds } 1 \text {, LAI }}$ growth of maize is reduced by a factor $\mathrm{e}^{(-\mathrm{kw} . L A I w e e d)}$. The water balance for maize was replaced by a water balance for maize, plus weeds. Thus, LAI was substituted by (LAI + $\left.\mathrm{LAI}_{\text {weed }}\right)$ in the functions used to calculate potential transpiration and evaporation. The root system of maize and weeds was considered to be a single unit and taken to behave in the same way as a pure maize crop, except that root growth starts with the emergence of the first emerging species (being weeds when maize sowing is done at least one day after the last soil tillage, and maize in the opposite case). Water stress is thus common to maize and weeds. Its dynamics are influenced by weeds by way of their impact on the total water demand. Nitrogen demand is calculated for the maize-weed association, for which the maize biomass calculated by Stics is replaced in the relevant equations by the sum of the maize and weed biomass, the latter being weighted by a calibration constant. $\mathrm{N}$ absorption is partitioned between maize and weeds in proportion to their relative biomass. $\mathrm{SN}_{\text {weed }}$ is calculated in a similar way to that for nitrogen stress on maize, where a critical $\mathrm{N}$ concentration in weeds is set, below which the $\mathrm{SN}_{\text {weed }}$ is equal to the ratio between actual and critical $\mathrm{N}$ concentrations. The critical $\mathrm{N}$ concentration in weeds is obtained by applying the generic function of Stics for $\mathrm{C}_{3}$ species without any modification.

\section{REFERENCES}

[1] Abruna F., Rodriquez J., Silva S., Crop response to soil acidity factors in Ultisols and Oxisols in Puerto Rico. VI. Grain sorghum, J. Agric. Univ. P.R. 61 (1982) 28-38.

[2] Adámoli J., Macedo J., Azevedo L.G., Madeira Netto J.S., Caracterização da região dos cerrados, in: Goedert W.J. (Ed.), Solos dos cerrados: tecnologias e estraégias de manejo, Nobel, São Paulo, 1987, pp. 33-98.

[3] Affholder F., Modélisation de culture et diagnostic agronomique régional. Mise au point d'une méthode et application au cas du maïs chez les petits producteurs du Brésil Central, Ph.-D. Thesis, INA-PG, Paris, 2001, 246 p.

[4] Aubry C., Latiri Souki K., Doré T., Griner C., Analysis of factors limiting durum wheat yield in farmers' fields in a small semi-arid area in Tunisia, Agronomie 14 (1994) 213-227.

[5] Becker M., Johnson D.E., Rice yield and productivity gaps in irrigated systems of the forest zone of Côte d'Ivoire, Field Crops Res. 60 (1999) 201-208.

[6] Boiffin J., Caneill J., Meynard J.M., Sebillotte M., Élaboration du rendement et fertilisation du blé d'hiver en champagne crayeuse (France) : 1. Protocole et méthode d'étude d'un problème technique régional, Agronomie 1 (1981) 549-558.
[7] Bonnal P., Modernizacao da agricultura camponesa e estrategia dos produtores: Projeto Silvania, estado de Goias, Brasil, Documentos, Vol. 55, Empresa Brasileira de Pesquisa Agropecuaria. Centro de Pesquisa Agropecuaria dos Cerrados, Planaltina DF, 1994.

[8] Bonnal P., Chaib Filho H., Madeira J.S.N., Paniago J.R.E., Santos N.A., Souza G.L.C., Sperry S., Zoby L.F., Síntese do projeto Silvânia (1986-1994), EMBRAPA-CPAC/CIRAD-SAR, Brasilia, 1994.

[9] Bonnal P., Xavier J.H.V., dos Santos N.A., Zoby J.L.F., Gastal M.L., Pereira E.A., Paniago E. Jr., de Souza J.B., O papel da rede de fazendas de referência no enfoque de pesquisa-desenvolvimento, in: Encontro em sistemas de produção, IAPAR, Londrina, Brazil, 1994, 24 p.

[10] Boyer J., L'aluminium échangeable : incidence agronomique. Evaluation et correction de sa toxicité dans les sols tropicaux, Cah. ORSTOM, Sér. Pédol. 14 (1976) 259-269.

[11] Brenes E., Pearson R.W., Root response of three gramineae species to soil acidity in an Oxisol and an Ultisol, Soil Sci. 116 (1973) 295-302.

[12] Brisson N., Mary B., Ripoche D., Jeuffroy M.H., Ruget F., Nicoullaud B., Gate P., Devienne Barret F., Antonioletti R., Durr C., Richard G., Beaudoin N., Recous S., Tayot X., Plenet D., Cellier P., Machet J.M., Meynard J.M., Delecolle R., STICS: a generic model for the simulation of crops and their water and nitrogen balances. I. Theory and parameterization applied to wheat and corn, Agronomie 18 (1998) 311-346.

[13] Coquillard P., Hill D.R.C., Modélisation et simulation d'écosystèmes : des modèles déterministes aux simulations à événements discrets, Masson, Paris, 1997.

[14] Cousens R., A simple model relating yield loss to weed density, Ann. Appl. Biol. 107 (1985) 239-252.

[15] Dias L.E., Carvalho L.J.C.B., Ritchey K.D., Avaliação da deficiência de $\mathrm{Ca}$ em diferentes solos de cerrado, por meio de crescimento de raízes, Rev. Ceres 32 (1985) 102-109.

[16] Diouf M., Analyse de l'élaboration du rendement du mil (Pennisetum typhoides Stapf et Hubb.). Mise au point d'une méthode de diagnostic en parcelles paysannes, Ph.-D. Thesis, INA-PG, Paris, 1990, $227 \mathrm{p}$.

[17] Donnars C., Peyrache X., Marzin J., Kalms J.M., Évolution de l'agriculture dans une région de savane : l'exemple de Silvania, Goias, Brésil, Cah. Rech.-Dév. 33 (1993) 61-69.

[18] Doré T., Sebillotte M., Meynard J.M., A diagnostic method for assessing regional variations in crop yield, Agric. Syst. 54 (1997) 169-188.

[19] Fujisaka S., A set of farmer-based diagnostic methods for setting post 'green revolution' rice research priorities, Agric. Syst. 36 (1991) 191-206

[20] Goedert W.J., Gomes de Souza D.M., Lobato E., Fosforo., in: Goedert W.J. (Ed.), Solos dos cerrados: tecnologias e estraégias de manejo, Nobel, São Paulo, 1987, pp. 129-166.

[21] Gomes de Souza D., Carvalho L.J., Miranda L.N., Correção da acidez do solo, in: Goedert W.J. (Ed.), Solos dos cerrados: tecnologias e estraégias de manejo, Nobel, São Paulo, 1985, pp. 99-127.

[22] Graf B., Gutierrez A.P., Rakotobe K., Zahner P., Delucchi V., A simulation model for the dynamics of rice growth and development: Part II- The competition with weeds for nitrogen and light, Agric. Syst. 32 (1990) 367-392.

[23] Kalivas D.P., Kollias V.J., Effects of soil, climate and cultivation techniques on cotton yield in Central Greece, using different statistical methods, Agronomie 21 (2001) 73-90.

[24] Kiniry J.R., Williams J.R., Gassman P.W., Debaeke P., A general, process-oriented model for two competing plant species, Trans. ASAE 35 (1992) 801-810.

[25] Kropff M.J., Spitters C.J.T., An eco-physiological model for interspecific competition, applied to the influence of Chenopodium album L. on sugar beet. I. Model description and parameterization, Weed Res. 32 (1992) 437-450. 
[26] Latiri-Souki K., Aubry C., Doré T., Sebillotte M., Élaboration du rendement du blé dur en conditions semi-arides en Tunisie: relations entre composantes du rendement sous différents régime de nutrition azotée et hydrique, Agronomie 12 (1992) 31-43.

[27] Leterme P., Manichon H., Roger-Estrade J., Analyse intégrée des rendements du blé tendre et de leurs causes de variation dans un réseau de parcelles d'agriculteurs du Thymerais, Agronomie 14 (1994) 341-361.

[28] Lizaso J.I., Ritchie J.T., A modified version of CERES to predict the impact of soil water excess on maize crop growth and development, in: Kropff M.J. (Ed.), Applications of Systems Approaches at the Field Level, Kluwer Academic Publishers, 1997, pp. 153-167.

[29] Manichon H., Influence des systèmes de culture sur le profil cultural : élaboration d'une méthode de diagnostic basée sur l'observation morphologique, Ph.-D. Thesis, INA-PG, Paris, 1982, $214 \mathrm{p}$.

[30] Meynard J.M., Sebillotte M., Diagnostic sur les causes de variation du rendement du blé dans une petite région, in: La fatigue des sols, Colloques de l'INRA, No. 17, 1983, pp. 157-168.

[31] Mitchell P.L., Sheehy J.E., Comparison of predictions and observations to assess model performance: a method of empirical validation, in: Kropff M.J. (Ed.), Applications of System Approaches at the Field Level, Kluwer Academic Publishers, 1997, pp. 437-451.

[32] Muchow R.C., Bellamy J.A. (Eds.), Climatic Risk in Crop Production: Models and Management for Semiarid Tropics and Subtropics, Proc. Int. Symposium, Brisbane, Australia, July 1990, C.A.B. International, Wallingford, UK, 1991.

[33] Passioura J.B., Simulation models: science, snake oil, education, or engineering?, Agron. J. 88 (1996) 690-694.

[34] Pavan M.A., Bingham F.T., Pratt P.F., Toxicity of aluminum to coffee in Ultisols and Oxisols amended with $\mathrm{CaCO}_{3}, \mathrm{MgCO}_{3}$, and $\mathrm{CaSO}_{4} \cdot 2 \mathrm{H}_{2} \mathrm{O}$, Soil Sci. Soc. Am. J. 46 (1982) 1201-1207.

[35] Reynolds J.F., Acock B., predicting the response of plants to increasing carbon dioxin: A critique of plant growth models, Ecol. Modell. 29 (1985) 107-129.
[36] Ritchey K.D., Sousa D.M.G., Silva J.E., Calcium and root penetration in highly weathered soils, in: Salinas J.G., Gourley L.M. (Eds.), Sorghum for acid soils. Evaluating sorghum for tolerance to Al-toxic tropical soils in Latin America, Centro Internacional de Agricultura Tropical, Cali, Columbia, 1984, pp. 117-132.

[37] Scopel E., Le semis direct avec paillis de résidus dans la région de V. Carranza au Mexique : intérêt de cette technique pour améliorer l'alimentation hydrique du maïs pluvial en zones à pluviométrie irrégulière, Ph.-D. Thesis, INA-PG, Paris, 1994, 211 p.

[38] Silva F.A.M.d., Assad E.D., Luiz A.J.B., Oliveira A.C., Probabilidade de ocorrência de chuva no Estado de Goiás, Documentos, Vol. 72, EMBRAPA-Centro de Pesquisa Agropecuária dos Cerrados, Planaltina DF, 1998.

[39] Silva J.E.d., Ritchey K.D., Lixiviação de cálcio e crescimento de raízes em oxissolos de cerrados, Proc. of the VI Simp. sobre o Cerrado. Savanas: Alimento e Energia, EMBRAPA-CPAC, Brasília DF, 1982, pp. 707-725.

[40] Sinclair T.M., Seligman N.G., Crop modelling: from infancy to maturity, Agron. J. 88 (1996) 698-704.

[41] Spitters C.J.T., Crop growth models: their usefulness and limitations, Acta Hortic. 267 (1990) 349-368.

[42] Vilela L., Euripides da Silva J., Ritchey K.D., Gomes de Sousa D.M., Potassio, in: Goedert W.J. (Ed.), Solos dos cerrados: tecnologias e estraégias de manejo, Nobel, São Paulo, 1987, pp. 129-166.

[43] Wey J., Oliver R., Manichon H., Siband P., Analysis of local limitations to maize yield under tropical conditions, Agronomie 18 (1998) 545-561.

[44] Wiles L.J., Wilkerson G.G., Modeling Competition for Light between Soybean and Broadleaf Weeds, Agric. Syst. 35 (1991) $37-51$.

[45] Wilkerson G.G., Coble H.D., Modena S.A., A post-emergence herbicide decision model for soybeans, Abstr. Weed Sci. Soc. Am. 27 (1987) 95. 